\title{
Distinct morphogenetic functions of similar small GTPases: Drosophila Drac1 is involved in axonal outgrowth and myoblast fusion
}

\author{
Liqun Luo, Y. Joyce Liao, Lily Yeh Jan, and Yuh Nung Jan
}

Howard Hughes Medical Institute, Departments of Physiology and Biochemistry University of California at San Francisco, San Francisco, California 94143 USA

The small GTPases of the Rac/Rho/Cdc42 subfamily are implicated in actin cytoskeleton-membrane interaction in mammalian cells and budding yeast. The in vivo functions of these GTPases in multicellular organisms are not known. We have cloned Drosophila homologs of rac and CDC42, Drac1, and Dcdc42. They share $\mathbf{7 0 \%}$ amino acid sequence identity with each other, and both are highly expressed in the nervous system and mesoderm during neuronal and muscle differentiation, respectively. We expressed putative constitutively active and dominant-negative Drac1 proteins in these tissues. When expressed in neurons, Drac1 mutant proteins cause axon outgrowth defects in peripheral neurons without affecting dendrites. When expressed in muscle precursors, they cause complete failure of, or abnormality in, myoblast fusion. Expressions of analogous mutant Dcdc42 proteins cause qualitatively distinct morphological defects, suggesting that similar GTPases in the same subfamily have unique roles in morphogenesis.

[Key Words: Drac1; Dcdc42; polarity; neuronal morphogenesis; muscle morphogenesis]

Received April 19, 1994; revised version accepted June 13, 1994.

Following the establishment of the body plan and the commitment of cell fates, one important step in the development of a multicellular organism is the morphological differentiation of different cell types. In the nervous system, for instance, neurons extend dendrites to receive signals and axons to send signals. In muscle, myoblasts fuse to form multinucleated muscle fibers. It is assumed that certain tissue-specific proteins will be activated after cell fate determination to execute the morphological differentiation process. However, the molecular mechanisms involved in neuronal and muscle morphogenesis are not well understood.

In Drosophila, genetic screens to isolate mutations have yielded much insight into the organization of body plan (Nüsslein-Volhard and Wieschaus 1980) and the specification of cell fate (for review, see Rubin 1991; Ghysen et al. 1993). The same approach has been applied to isolate mutations affecting axon guidance (Seeger et al. 1993; Van Vactor et al. 1993). In general, for later developmental processes, such a strategy may face several complexities. For genes that are required at multiple times and in multiple places, a mutant phenotype of the first developmental defect may mask later phenotypes. Defects in multiple tissues also make it difficult to distinguish the cause from the effect.

We are interested in identifying genes involved in neuronal morphogenesis. One strategy is to create dominant mutations in candidate genes and to express them in a temporal and tissue-specific manner, as described by Brand and Perrimon (1993). We have explored the possibility that aspects of neuronal morphogenesis such as axonal and dendritic outgrowth may share similar molecular mechanisms as the budding of yeast Saccharomyces cerevisiae. From a cell biological point of view, both processes are brought about via polarized secretion and plasma membrane addition.

Genetic analysis of yeast budding has divided this complex process into two major steps consisting of bud site selection and bud site assembly (Chant and Herskowitz 1991; Drubin 1991). Small GTPases of the Ras superfamily (Bender and Pringle 1989; Johnson and Pringle 1990), their associated guanine nucleotide exchange factors (Chant et al. 1991; Hart et al. 1991; Powers et al. 1991; Ron et al. 1991), and GTPase-activating proteins (GAP) (Park et al. 1993) play prominent roles in both events. In particular, the Cdc 42 protein product is essential for bud site assembly (Johnson and Pringle 1990). A human Cdc42 homolog has been identified (Shinjo et al. 1990), yet the function of Cdc42 in multicellular organisms is unknown. Cdc42 belongs to the same GTPase subfamily as the proteins Rac and Rho, which have been implicated in membrane-actin cytoskeleton interactions. In fibroblasts, Rho has been shown to regulate stress fiber formation, whereas Rac regulates membrane 
ruffling in response to serum stimulation (Ridley and Hall 1992; Ridley et al. 1992). To date, two Rac proteins have been described in human: Racl has a ubiquitous expression pattern, and Rac2 is restricted to the hemopoietic cell lineage (Didsbury et al. 1989). The functions of these molecules in morphogenesis in vivo are not known.

In this paper we report the characterization of two Drosophila genes, Drac1 and Dcdc42. Both are expressed in the nervous system at the time of axonogenesis and in muscle precursors at the time of myoblast fusion. Expression of putative constitutively active or dominantnegative Drac1 mutants in the nervous system or in mesoderm results in defective axon outgrowth or myoblast fusion, respectively. Expression of analogous Dcdc42 mutants generates morphological defects that are qualitatively distinct from those of the corresponding Dracl mutants. Thus, it appears that similar GTPases in the same subfamily have unique roles in morphogenesis in vivo.

\section{Results}

\section{Cloning of Dracl and Dcdc42}

We isolated first PCR fragments and then cDNAs encoding the entire open reading frame (ORF) of Drac1 and Dcdc42 from a 0- to 12-hr Drosophila embryonic cDNA library (see Materials and methods). The Drac1 nucleotide sequence predicts a 192-amino-acid protein with $92 \%$ sequence identity to human Rac1 and $89 \%$ identity to human Rac2. All of the essential features of the GTPases, including the nucleotide-binding pocket and the carboxy-terminal post-translational processing signal (Bourne et al. 1991), are well conserved among Dracl and the two human Rac proteins. Most of the divergent sequences are near the carboxy-terminal "hypervariable" region (amino acids 180-185).
The $\operatorname{Dcdc42}$ nucleotide sequence translates into a 191amino-acid protein with $93 \%$ sequence identity to human $\mathrm{Cdc} 42$ (Cdc42Hs) and $79 \%$ identity to yeast $\mathrm{Cdc} 42$ (Cdc42Sc) (Fig. 1B). The amino terminus is highly conserved among flies, human, and yeast. Most of the different amino acids reside in the carboxyl terminus. Dracl and Dcdc42 share $70 \%$ amino acid sequence identity (Fig. 1C). Most of the differences reside in the last two-thirds of the proteins (amino acids 80-192). In the amino terminus there is one region of divergence (amino acids 26-56) that is flanked by well-conserved regions.

\section{Expression of Dracl in embryogenesis}

A single major transcript of $2.4 \mathrm{~kb}$ for Drac1 and $2.3 \mathrm{~kb}$ for $D c d c 42$ was identified on a Northern blot of embryonic mRNA (Fig. 2A,B). Both transcripts were detected throughout development (data not shown). Strong and ubiquitous expression of Drac1 RNA was evident in precellular (data not shown) as well as cellular blastoderm stages (Fig. 2C). The transcript is concentrated at the basal part of cellular blastoderm (Fig. 2C). After gastrulation, Drac1 transcripts become highly enriched in mesoderm between stages 10 and 12 (staging according to Campos-Ortega and Hartenstein 1985; Fig. 2D|. At stage 13, Drac1 transcripts start to appear in the nervous system and the gut (Fig. 2E). Later in development, somatic mesoderm expression vanishes, whereas the nervous system and gut expression persists (Fig. 2F). Interestingly, the expression pattern of $D c d c 42$ is qualitatively similar to that of Drac1 in all of the stages described above (data not shown). This similarity cannot be caused by the cross-reactivity of the RNA probes (they share $60 \%$ identity in nucleotide sequences), because under the same condition, a probe from Drac2 (which shares $80 \%$ nucleotide sequence identity with the Drac1 probe; see Materials and methods) labels predominantly the vis-
Figure 1. Amino acid sequences of Dracl and Dcdc42. The sequence at the top is the guide for comparison for sequences below. (:) Amino acid identity; divergent amino acids are indicated. (-) Gaps introduced to maximize alignment. Numeration of the protein sequence begins with the initiation methionine and ends with the last codon before the stop codon. $(A)$ Amino acid sequence of Dracl is aligned with those of human Racl (raclHs) and human Rac2 (rac2Hs). Dracl is $92 \%$ identical or $95 \%$ similar to rac $1 \mathrm{Hs}$ and $89 \%$ identical or $95 \%$ similar to rac2Hs. (Similarity is calculated assuming the following amino acids are conservative changes: $A, S$, and $T ; D, E, N$, and $Q ; R$ and $K ; I, L, M$, and $V ; F, Y$, and W.) (B) Amino acid sequence of Dcdc42 is aligned with those of human (Cdc42Hs) and yeast (Cdc42Sc) Cdc42. Dcdc42 is $93 \%$ identical or $95 \%$ similar to Cdc $42 \mathrm{Hs}$ and $79 \%$ identical or $86 \%$ similar to Cdc42Sc. $(\mathrm{C})$ Amino acid sequences of Drac1 and Dcdc42 are aligned. They share $70 \%$ amino acid identity and $79 \%$ similarity.

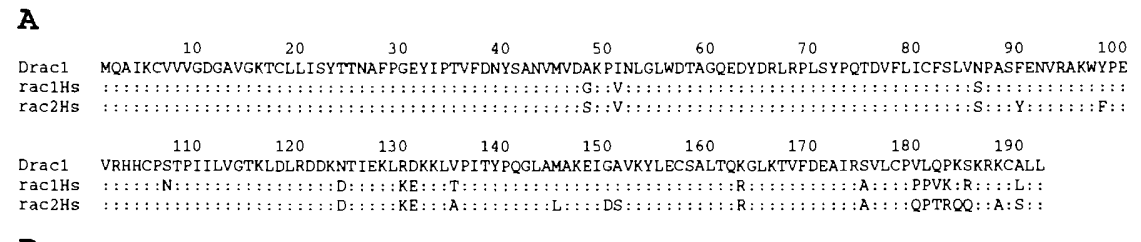

$\mathbf{B}$

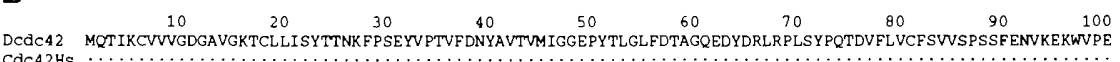

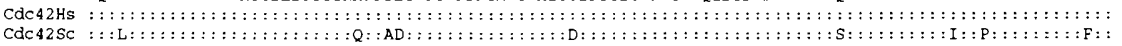

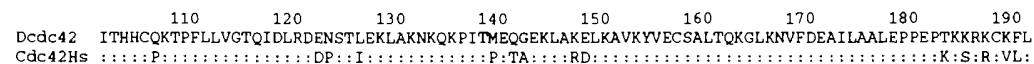

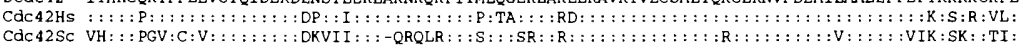
C

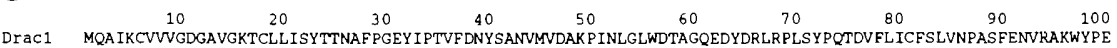

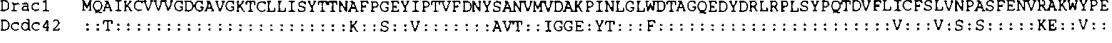

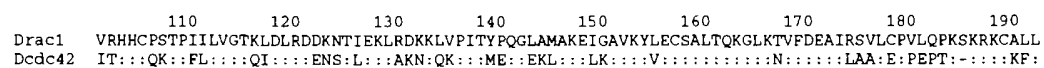



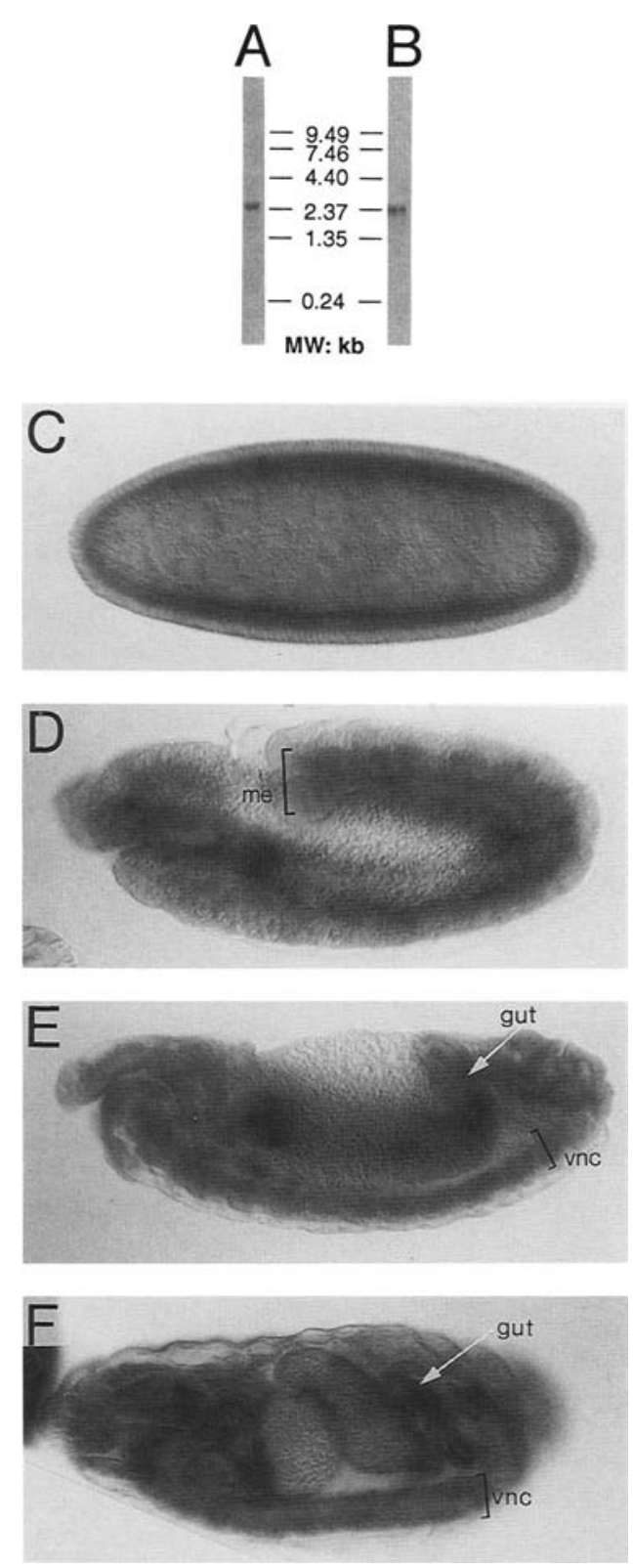

Figure 2. Expression of the Drac1 transcript during embryogenesis. $(A, B)$ A single major band of $2.4 \mathrm{~kb}(A)$ and $2.3 \mathrm{~kb}(B)$ was detected on a Northern blot of $4 \mu \mathrm{g}$ of poly $(\mathrm{A})^{+}$mRNA of 12- to 16-hr embryos probed with $\operatorname{Drac1}(A)$ and $\operatorname{Dcdc42}(B)$ cDNA. $(C)$ Drac1 is expressed ubiquitously at the cellular blastoderm stage. The transcripts are concentrated in the basal part of the cells. $(D)$ At stage 11, Drac1 is highly enriched in the mesoderm. (E) At stage 13, the nervous system and the gut start to express Drac1. $(F)$ At stage 16, Drac1 expression persists in the nervous system and the gut but diminishes in somatic mesoderm. In this and subsequent figures unless otherwise mentioned, all embryos are oriented dorsal side up with anterior to the left. (me) Mesoderm; (vnc) ventral nerve cord.

ceral mesoderm (data not shown). The expression of Drac1 and Dcdc42 in the nervous system in stage 13 at the time of axonogenesis and in mesoderm at the time of muscle formation prompted us to investigate their roles in these processes.

Tissue-specific expression of dominant mutants as an experimental strategy to study the in vivo function of Drac1

The available information on constitutively active and dominant-negative mutants in Rac (Ridley et al. 1992) was employed to study Dracl function by expressing dominant mutants in a tissue-specific manner. This approach was taken not only because no mutants or chromosomal deletions of Drac1 (at chromosomal location 61F) were currently available but also because it circumvents the problem of potential pleiotropic effects of a Drac1 mutant and the likely maternal rescue of the early phenotypes.

Point mutations in three different positions of Dracl were generated-V12, N17, and L89. V12 (Val-12 for Gly12) mutation was originally identified in an oncogenic form of Ras and later shown to render Ras constitutively active as a result of defective GTPase activity (for review, see Barbacid 1987). N17 (Asn-17 for Thr-17) mutation was originally identified biochemically in Ras by its preferential binding to GDP relative to GTP (Feig and Cooper 1988). RasN17 may function as a dominant-negative mutant by sequestering the rate-limiting guanine nucleotide exchange factor (Schweighoffer et al. 1993). More significantly, V12 and N17 mutations in human Racl, which shares $92 \%$ amino acid sequence identity with Dracl, were shown to work as constitutively active and dominant-negative proteins, respectively, in fibroblasts (Ridley et al. 1992). F89 (Phe-89 for Ser-89) mutation was identified in the ras homolog let60 of Caenorhabditis elegans that gives a dominant-negative phenotype in vulval development (Beitel et al. 1990; Han and Sternberg 1991). It is hypothesized to work in a fashion similar to N17 (Han and Sternberg 1991). We introduced each of these three mutations in Dracl individually, with the amino acid 89 position mutated from Ser to Leu instead of Phe. For simplicity, even though we do not have direct biochemical data on Dracl mutant proteins, we will refer to these mutants as constitutively active (V12) and dominant negative (N17 and L89) hereafter. The phenotypes generated by the coexpression of wild-type Dracl with the mutants are consistent with the above hypothesis (see Tables 1 and 2, below).

To express the dominant mutants in a specific tissue or cell type, we used the GAL4 system recently established by Brand and Perrimon (1993). We subcloned Drac1 mutant genes into the pUAST vector and established transgenic lines. The pUAST vector contains the GAL4-responsive upstream activation sequence (UAS) and expresses the Dracl mutant proteins only in the presence of GAL4. We then crossed these transgenic flies to flies that express GAL4 in either neurons or muscle precursors by specific promoters or enhancer traps (Brand and Perrimon 1993). For all of the experiments shown below, at least two independent lines of pUAST GTPases were tested and were found to give similar re- 
sults. The GAL4-induced expression of Drac1 was verified by in situ hybridization (for an example, see Fig. $3 \mathrm{H}$ ).

Drac1 mutants block axon outgrowth

To express Drac1 in the nervous system, we used the
GAL4 enhancer trap lines GAL4-1407 and GAL4-60. GAL4-1407 expresses the reporter gene early in neuroblasts (at stage 10/11) and subsequently in most neurons of the central nervous system (CNS), and in all neurons of the peripheral nervous system (PNS) (Fig. 3A-C). GAL4-60 expresses the reporter in a subset of CNS neu-
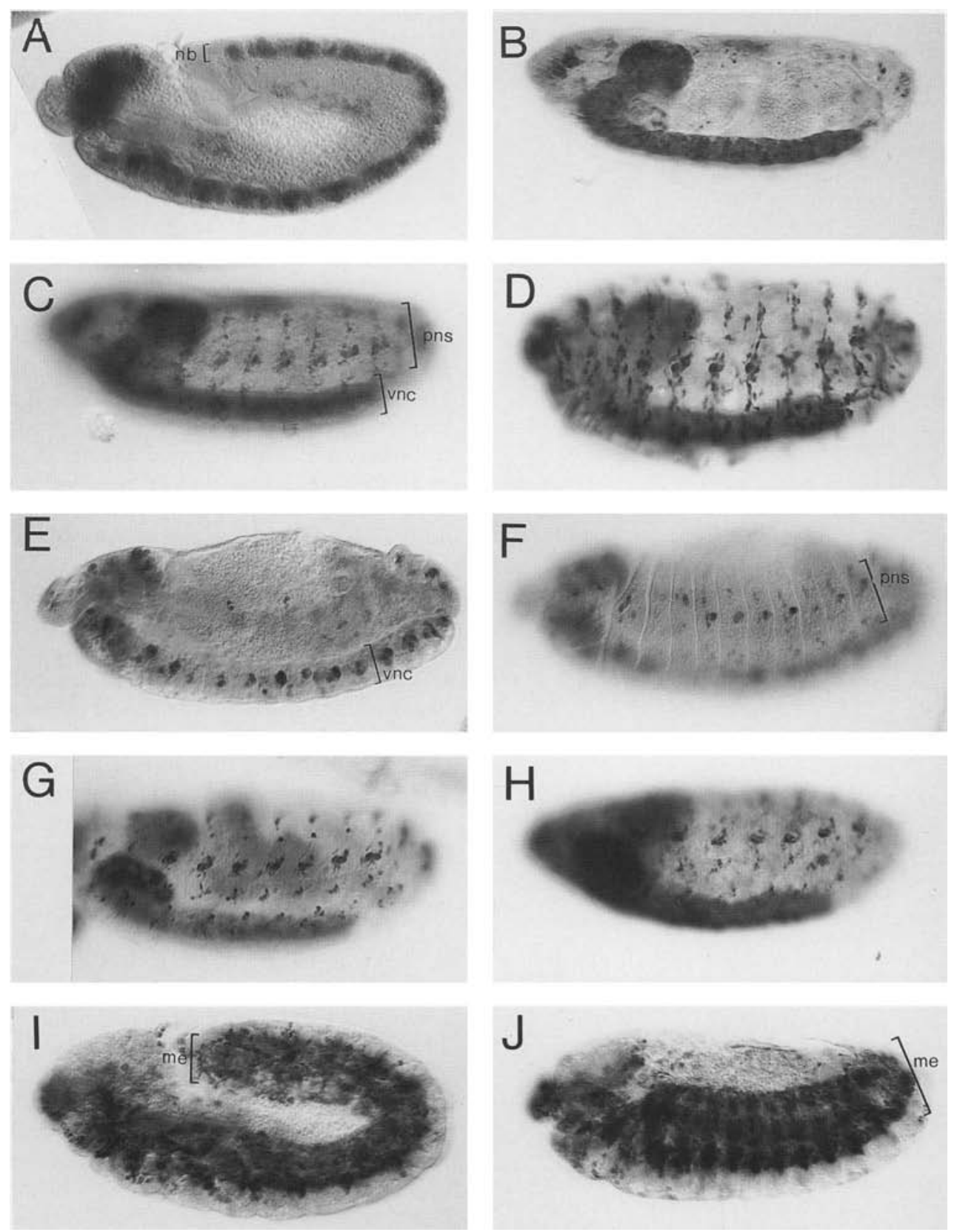

Figure 3. Expression pattern of the GAL4 lines revealed by the anti- $\beta$-gal staining of the embryos generated by crossing GAL4 expression lines with UAS-LacZ (except $H$ ). (A-C) In GAL4-1407;UAS-lacZ embryos, $\beta$-gal is expressed in the CNS neuroblast region $(A$, stage 11$)$ and in CNS and PNS neurons $(B, C$, stage 16$)$. (D) In a stage-16 elav-GAL4;UAS-lacZ embryo, $\beta$-gal is expressed in all PNS neurons and most, if not all, CNS neurons. (E-G) In GAL4-60;UAS-lacZ embryos at stages $13(E, F)$ and $16(G)$, $\beta$-gal is expressed in all PNS neurons and a small subset of CNS neurons. $(H)$ In a stage-16 GAL4-60; UAS-Drac1V12 embryo probed with a Drac1 RNA probe, the strong GAL4-driven expression of Drac1 in PNS and CNS neurons masks the endogenous Drac1 expression (cf. with Fig. $2 \mathrm{~F})$. (I-I) In GAL4-24B;UAS-lacZ embryos at stages $11(I)$ and $13(J), \beta$-gal is expressed in most, if not all, mesodermal cells starting from stage 11. All embryos are shown from a lateral view. (nb) Neuroblast; (vnc) ventral nerve cord; (pns) peripheral nervous system; (me) mesoderm. 
rons as well as all PNS neurons, with a later onset around stage 13 (Fig. 3E-G). We also constructed transgenic flies in which the neuronal-specific promoter from the gene elav (Robinow and White 1988; Yao and White 1994) drives GAL4 expression. elav-GAL4 expresses the reporter in all neurons in embryos starting at stage 12 (Fig. 3D).

Expression of wild-type Drac1 using the three nervous system GAL4 lines had no effect on embryonic viability (Table 1). In contrast, expression of the three UASDrac1 mutants in the nervous system caused embryonic lethality to various extents (Table 1). In the most extreme case (GAL4-1407; UAS-Drac1V12), all progeny are embryonic lethal.

To investigate the basis for embryonic lethality, we stained embryos generated from crossing homozygous GAL4 lines and homozygous UAS-Drac1 mutants with monoclonal antibody $22 \mathrm{C} 10$ to visualize the general anatomy of the PNS. mAb22C10 labels all the cell bodies, dendrites, and axons of the PNS (Hartenstein 1988).
In wild-type as well as in GAL4-1407;UAS-Drac1WT (overexpressing wild-type Dracl proteins) embryos, each segment contains three highly stereotyped clusters of PNS neurons (Bodmer and Jan 1987; Hartenstein 1988) connected by axon bundles (Fig. 4A, arrows).

When the dominant-negative Drac1L89 was expressed with the GAL4-1407 line, we observed occasional loss of axons between the dorsal and lateral clusters (contributed by afferent axons of the dorsal cluster neurons) (Fig. $4 \mathrm{~B}$, short arrows; also see Table 2). Two copies of UASDrac1L89 greatly increase the axonal loss (Table 2). Coexpressing a UAS-Drac1WT transgene ameliorates the axonal loss (Table 2), which is consistent with L89 being a weak dominant-negative mutation. Expression of constitutively active Drac1V12 with GAL4-1407 has a more severe axonal phenotype compared with that of Drac1L89. In this case, we observed axonal loss between the dorsal and the lateral clusters in most segments (Fig. $4 \mathrm{C}$, short arrows; Table 2). Sometimes the axons connecting the lateral and ventral clusters were also missing

Table 1. Lethality of various GAL4 line and UAS-Drac1 mutant combinations

\begin{tabular}{|c|c|c|c|c|}
\hline & $\begin{array}{l}\text { GAL4-1407 } \\
\text { (neuronal precursors } \\
\text { and neurons) }\end{array}$ & $\begin{array}{l}\text { elav-GAL4 } \\
\text { (postmitotic } \\
\text { neurons, all CNS } \\
\text { and PNS) }\end{array}$ & $\begin{array}{l}\text { GAL4-60 } \\
\text { (postmitotic neurons, } \\
\text { CNS subset, all PNS) }\end{array}$ & $\begin{array}{l}\text { GAL4-24B } \\
\text { (mesoderm) }\end{array}$ \\
\hline $\begin{array}{l}\text { UAS-Drac1 (wild } \\
\text { type, based on line } \\
\text { WT.3) }\end{array}$ & $0 \% \mathrm{EL}^{\mathrm{a}}$ viable adult ${ }^{\mathrm{b}}$ & $2 \%$ EL viable adult ${ }^{b}$ & $0 \%$ EL viable adult ${ }^{\mathrm{b}}$ & $0 \%$ EL $100 \% \mathrm{LL}^{\mathrm{a}}$ \\
\hline $\begin{array}{l}\text { UAS-Drac1V12 } \\
\text { (constitutively } \\
\text { active, based on } \\
\text { line V12.1) }\end{array}$ & $\begin{array}{l}100 \% \text { EL little muscle } \\
\text { contraction }\end{array}$ & $\begin{array}{l}100 \% \mathrm{EL} \\
\text { spontaneous and } \\
\text { evoked muscle } \\
\text { contraction }\end{array}$ & $\begin{array}{l}94 \% \text { EL, spontaneous } \\
\text { and evoked muscle } \\
\text { contraction }\end{array}$ & $\begin{array}{c}100 \% \mathrm{EL}, \text { no muscle } \\
\text { contraction, gut and } \\
\text { tracheal abnormal }\end{array}$ \\
\hline $\begin{array}{l}\text { UAS-Drac1N17 } \\
\text { (dominant negative, } \\
\text { based on line } \\
\text { N17.1) }\end{array}$ & $44 \%$ EL viable adul $t^{\mathrm{b}}$ & $43 \%$ EL viable adult ${ }^{b}$ & $0 \%$ EL viable adult ${ }^{\mathrm{b}}$ & $\begin{array}{l}99 \% \mathrm{EL}^{\mathrm{c}} \text { weak muscle } \\
\text { contraction }\end{array}$ \\
\hline $\begin{array}{l}\text { UAS-Drac1L89 } \\
\text { (dominant negative, } \\
\text { based on line L89.6) }\end{array}$ & $\begin{array}{l}15 \% \mathrm{EL} \text {, minimum } \\
\text { larval activity } \\
100 \% 1 \mathrm{LL}^{\mathrm{a}}\end{array}$ & $15 \%$ EL viable adult ${ }^{\mathrm{b}}$ & $\begin{array}{l}1 \% \mathrm{EL} \text {, initial larval } \\
\text { activity } \mathrm{OK} \\
100 \% 1 \mathrm{LL}\end{array}$ & $88 \%$ EL $100 \% 1 L^{a}$ \\
\hline $\begin{array}{l}U A S-D c d c 42 V 12 \\
\text { (constitutively } \\
\text { active, based on } \\
\text { line V12.2) }\end{array}$ & $\begin{array}{l}100 \% \text { EL, little } \\
\text { muscle contraction }\end{array}$ & N.D. ${ }^{d}$ & N.D. & $\begin{array}{l}97 \% \text { EL, spontaneous } \\
\text { and evoked muscle } \\
\text { contraction }\end{array}$ \\
\hline $\begin{array}{l}\text { UAS-Dcdc42N17 } \\
\text { (dominant negative, } \\
\text { based on line } \\
\text { N17.3) }\end{array}$ & $42 \%$ EL viable adult ${ }^{\mathrm{b}}$ & N.D. & N.D. & $\begin{array}{l}10 \% \text { EL, most pupae } \\
\text { die right before } \\
\text { eclosion }\end{array}$ \\
\hline
\end{tabular}

Homozygous GAL4 lines were crossed to homozygous UAS-Drac1 wild-type or mutant lines, and embryos were collected on grape juice agar plates. Embryo cases were counted as hatched embryos $26-30 \mathrm{hr}$ after egg laying $\left(25^{\circ} \mathrm{C}\right)$. Unhatched embryos were also counted, dechorionated, and observed for general structures and movement. Unfertilized eggs were discarded at this stage in calculating embryonic lethality rate. At least 100 embryos were used for each quantitation experiment.

a(EL) Embryonic lethal; (1LL) first instar larval lethal; (LL) larval lethal.

bViable adult means that some animals reach adulthood; no quantitation of percentage of viable adult was attempted.

${ }^{\mathrm{c}}$ GAL-24B;UAS-Drac1WT.3;UAS-Drac1N17.1 (coexpressing wild-type Drac1 together with Drac1N17) has a significantly higher embryonic viability rate $(4.7 \pm 2.6 \%$, mean \pm S.D. $)$ than that of $G A L-24 B ; U A S-D r a c 1 N 17.1(0.76 \pm 0.3 \%)(t$-test, $P<0.005)$, thereby supporting the hypothesis that $\mathrm{N} 17$ acts as a dominant negative mutant.

${ }^{\mathrm{d}}$ Not determined. 
Figure 4. Embryos expressing mutant Drac1 in neurons exhibit axon outgrowth defects, as revealed by mAb $22 \mathrm{C} 10$ staining. $(A)$ In a wild-type stage-16 embryo, $\mathrm{mAb} 22 \mathrm{C} 10$ stains segmentally repeated cell bodies of the PNS neurons of the dorsal and lateral clusters, their dendrites (arrowhead), and the axons connecting the dorsal and lateral clusters (long arrow). $(B)$ In a GAL4-1407; UAS-Drac1L89 (two copies) embryo at stage 16, some of the axons that normally extend between lateral and ventral clusters are missing (short arrow) whereas dendrites of the dorsal external neurons (dorsal to the dorsal cluster neurons) and the bidendritic neurons (ventral-most of the dorsal cluster neurons) are present (arrowheads). (C) In a GAL4-1407;UASDrac1V12 embryo at stage 15 , the axons between the dorsal and the lateral clusters are missing in most segments (short arrow) whereas dendrites such as dorsal es dendrites (arrowhead) are still present. $(D)$ In an elav-GAL4;UAS-Drac1V12 embryo at stage 16, axons between the dorsal and the lateral clusters are missing (short arrow) or stalled along the pathway in a few segments (asterisk) whereas dendrites are still present (arrowheads). $\{E\rangle$ A high magnification picture of the same embryo in $D(4 \times)$ is shown. The growth cone of the stalled axon is clearly visible $(*)$. All embryos are shown from a dorsal-lateral view. Long arrows indicate the wild-type axons, short arrows designate the missing axons, and arrowheads represent the dendrites of the dorsal external sensory and bidendritic neurons.

(Fig. 4C, short arrow). Examination of mutant embryos at earlier stages suggests that no detectable axons were ever formed in the mutant clusters (data not shown).

We wonder whether Dracl mutant could also affect axon elongation in addition to initiation. We tested this by expressing DraclV12 using elav-GAL4, which has a later onset of GAL4 expression in the PNS. A small percentage of the axons between dorsal and lateral clusters were defective (Fig. 4D, short arrows; Table 2). Axons from the dorsal cluster were often stalled along the pathway toward the lateral cluster. The growth cones of the stalled axons are clearly visible (Fig. 4E, asterisk). These stalled axons are more likely to be permanently arrested than simply delayed, because in wild type the completion of the axons between dorsal and lateral clusters occurs well before the stages where these stalled axons can be found. Thus, in addition to affecting axon initiation, neuronal expression of Drac1V12 also affects axon elongation.

When UAS-Drac1V12 is expressed under a later onset nervous system expression line GAL4-60, there is no detectable morphological defect in mAb $22 \mathrm{Cl0}$ staining pattern (Table 2 ), although $94 \%$ of the progeny die as embryos (Table 1). This suggests that expression of DraclV12 in the nervous system could interfere with other vital functions in addition to perturbing the initiation and elongation of axon outgrowth.

We found that although axonal outgrowth is affected in the presence of mutant Dracl, other aspects of neuronal differentiation are not affected. Note that the number and position of $\mathrm{mAb} 22 \mathrm{C10}$-staining cells remain the same as in wild-type embryos (Fig. 4). In addition to $\mathrm{mAb}$ $22 \mathrm{C} 10$ antigen, other neuronal differentiation markers such as the horseradish peroxidase (HRP) antigen (Jan
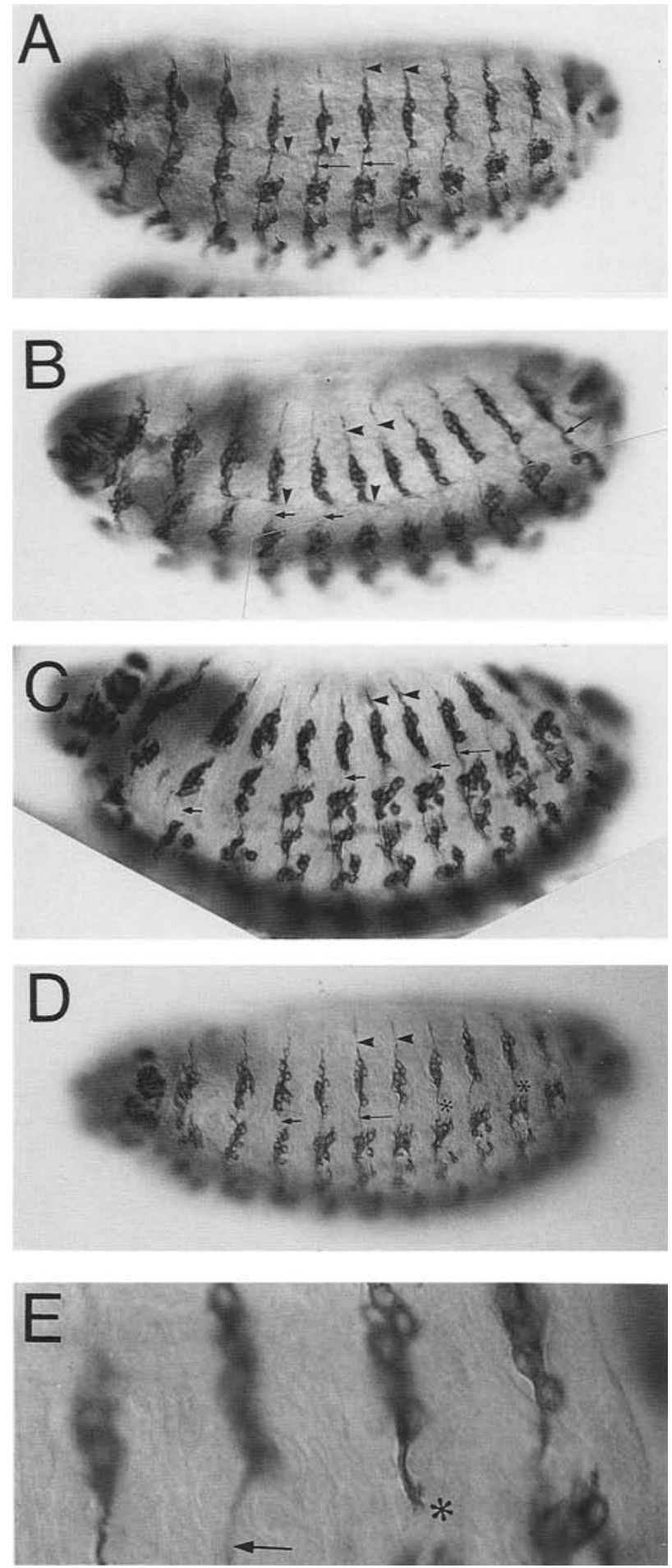

and Jan 1982) and the Drosophila synaptic vesicle-associated protein synaptotagmin (Littleton et al. 1993) also appear in these axonless neurons (data not shown). Interestingly, the identifiable dendrites of the PNS neurons, such as those of the dorsal external sensory neurons (Fig. 4B-D, arrowheads) and the dorsal bidendritic 
Table 2. Quantitation of axon defect in different genotypes

\begin{tabular}{|c|c|c|}
\hline Genotype $^{a}$ & Axon defect in 175 hemisegments $(\mathrm{A} 1-\mathrm{A} 7)^{\mathrm{b}}$ & Axon defect $(\%)$ \\
\hline \multicolumn{3}{|c|}{ Wild-type control (no Drac1 transgene) } \\
\hline 1. 1407 & 0 & 0 \\
\hline \multicolumn{3}{|l|}{ Expressing Drac1V12 mutant } \\
\hline 2. $1407 ; V 12.1(I I I)$ & 123 & 70 \\
\hline 3. $1407 ; V 12.9(I I I)$ & 96 & 55 \\
\hline \multicolumn{3}{|l|}{ Expressing Drac1L89 mutant } \\
\hline 4. $1407 ; L 89.2(I I I)$ & 2 & 1 \\
\hline 5. $1407 ; L 89.6(I I)$ & 7 & 4 \\
\hline 6. $1407 ; L 89.9(I I I)$ & 1 & 0.5 \\
\hline 7. $1407 ; L 89.22(I I)$ & 27 & 15 \\
\hline 8. $1407 ; L 89.6(I I) ; L 89.2(I I I)$ & 55 & 31 \\
\hline 9. $1407 ; L 89.22(I I) ; L 89.2(I I I)$ & 71 & 41 \\
\hline \multicolumn{3}{|c|}{$\begin{array}{l}\text { Expressing Drac1 wild type alone or in } \\
\text { combination with V12, L } 89 \text { mutant }\end{array}$} \\
\hline 10. $1407 ; W T .3(I I)$ & 0 & 0 \\
\hline 11. 1407;WT.3(II); V12.1(III) & 127 & 73 \\
\hline 12. $1407 ; W T .3(I I) ; L 89.2(I I I)$ & 0 & 0 \\
\hline 13. $1407 ; W T .3(I I) ; L 89.9(I I I)$ & 0 & 0 \\
\hline \multicolumn{3}{|l|}{ Expressing Drac1N17 mutant } \\
\hline 14. $1407 ; N 17.1(I I I)$ & 0 & 0 \\
\hline 15. $1407 ; N 17.12(I I I)$ & 0 & 0 \\
\hline \multicolumn{3}{|c|}{ Expressing Drac1V12 from other neuronal GAL4 lines } \\
\hline 16. elav-GAL4.1;V12.1(III) & 23 & 13 \\
\hline 17. $60 ; V 12.1(I I I)$ & 0 & 0 \\
\hline \multicolumn{3}{|c|}{ Expressing Drac1V12 from the muscle GAL4 line } \\
\hline 18. $24 B ; V 12.1(I I I)$ & 0 & $0^{\mathrm{c}}$ \\
\hline \multicolumn{3}{|c|}{ Expressing $D c d c 42$ mutants from GAL4-1407 } \\
\hline 19. 1407;Dcdc42V12.2(III) & 58 & 33 \\
\hline 20. $1407 ; D c d c 42 N 17.4(I I)$ & 0 & 0 \\
\hline
\end{tabular}

Homozygous GAL4 lines were crossed to homozygous UAS-Drac1 (wild-type or mutant) transgenes (rows 2-18), to homozygous $U A S-D c d c 42$ mutant (rows 19, 20) or to $w$, the host for all transgenes (row 1) as a control. Embryos were stained with mAb 22C10, and 25 embryos of stage 16 from each genotype were chosen for quantitation.

${ }^{a}$ GAL4 lines and UAS-Drac1 (wild type or mutant) are abbreviated (e.g., GAL4-1407 as 1407;UAS-Drac1V12.1 as V12.1). The last number represents each independent transgenic line. Roman numerals in parentheses indicate the chromosome location for each line. ${ }^{b}$ Axons from dorsal clusters to the lateral clusters of abdominal segments Al-A7 were used for quantitation. Only the complete missing, occasionally stalled, or misrouting of the entire axon bundle were scored as axon defects. This is a stringent criterion, as it does not include apparent thinning of axon bundles in mutant embryos possibly due to the loss of axons from a subset of dorsal cluster neurons.

'Together with the fact that 1407; UAS-Drac1V12 does not change any muscle phenotype revealed by MHC staining (data not shown), this experiment demonstrates the specificity of the GAL4 lines in generating the neuronal or muscle phenotypes.

neurons (Fig. 4B, arrowheads), appear intact in these embryos.

\section{Drac1V12 causes abnormal neuronal accumulation of F-actin}

Because the Rac subfamily of GTPases have been implicated in membrane-actin cytoskeleton interaction, the mutant Drac1's phenotype may be accompanied by a defect in cytoskeleton. We studied the actin distribution in the PNS neurons by confocal microscopy using double labeling of mAb $22 \mathrm{C} 10$ and phalloidin. Filamentous actins (F-actins), as revealed by phalloidin staining, are enriched in growth cones of neurons (e.g., see O'Connor and Bentley 1993|. Consistent with this, we observed that CNS nerve tracks in developing embryos are heavily stained with phalloidin (data not shown). In wild-type embryos after stage 15, when the growth cones of PNS neurons already reached CNS, no strong phalloidin staining can be found in the dorsal cluster that overlaps with mAb $22 \mathrm{Cl0}$ staining (Fig. 5A-C). In contrast, in GAL4-1407;UAS-Drac1V12 embryos, the strongest phalloidin staining in the dorsal cluster (Fig. 5E, lines defined by the arrows/ coincides with mAb 22C10 antigen $($ Fig. 5D,F $)$ even at stage 16 . The F-actin distribution in the dorsal cluster is not uniform; rather, it is accumulated in the ventral portion and appears to coincide with axon bundles within the dorsal clusters. Interestingly, in the mutant clusters of GAL4-1407;UAS-Drac1L89/two copies| embryo of the same stage, where no axons are visible between the dorsal and lateral clusters (in other focal planes), there is no accumulation of F-actin in the dorsal cluster as seen in GAL4-1407;UAS-Drac1V12 embryos (Fig. 5G-I). This suggests that the similar ax- 
Figure 5. Abnormal F-actin accumulation in DraclV12 mutant. $(A-C)$ An optic section of a wild-type stage-15 embryo with mAb 22Cl0 (green) $(A)$, phalloidin (red) $(B)$, and $\mathrm{mAb} 22 \mathrm{C} 10$ and phalloidin $(C)$ loverlap is yellow). Notice that there is no strong phalloidin staining in the two dorsal clusters defined by $\mathrm{mAb} 22 \mathrm{C} 10$ antigen in this embryo (arrows point to the analogous positions in three images) and all other embryos we observed past stage 15. $(D-F)$ An optic section of a GAL4-1407; UASDrac1V12 stage-16 embryo with mAb $22 \mathrm{Cl} 0$ (green) $(A)$, phalloidin (red) $(B)$, and $\mathrm{mAb} 22 \mathrm{Cl0}$ and phalloidin $(C)$ (overlap is yellow). The strong phalloidin staining coincides with the dorsal neuronal clusters in both segments (arrows point to the analogous positions in three images). $(G-I)$ An optic section of a GAL4-1407; UASDrac1L89 (two copies) stage-16 embryo with mAb 22C10 (green) (G), phalloidin (red) $(H)$, and $\mathrm{mAb} 22 \mathrm{Cl} 0$ and phalloidin $(I)$. No strong phalloidin staining coincides with the dorsal neuronal clusters, whereas the general phalloidin staining is similar to that of GAL4-1407; UAS-Drac1V12 (cf. H with $E)$.

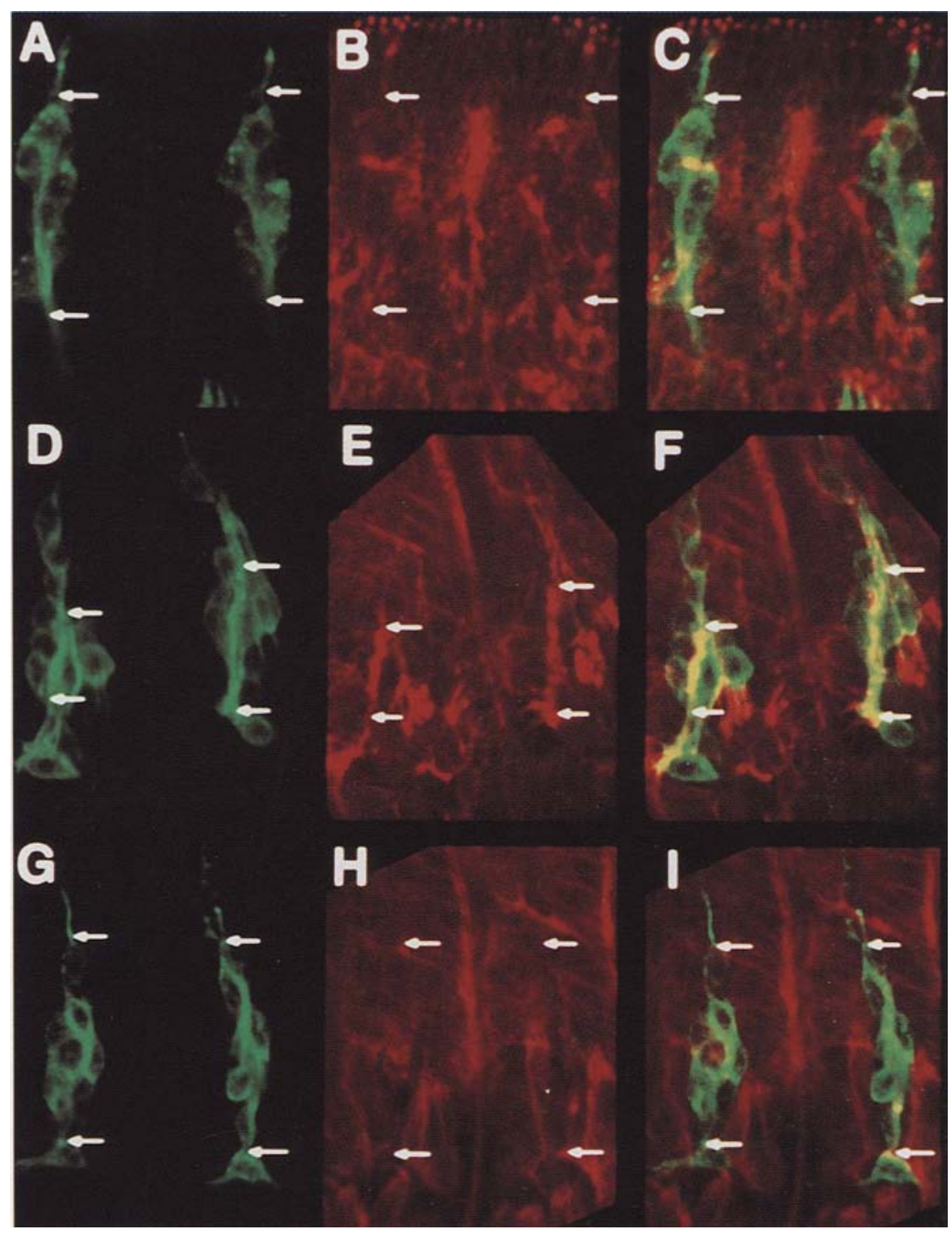

onal-loss phenotypes generated by expressing constitutively active (V12) and dominant-negative (L89) Dracl mutants probably arise from different cytoskeletal defects in neurons.

\section{Drac1 mutants disrupt myoblast fusion}

Because Drac1 is predominantly expressed in mesoderm at stage 12 (Fig. 2D), we investigated the function of Drac1 in muscle development by expressing mutant Dracl proteins under the control of a mesoderm line GAL4-24B. GAL4-24B expresses the reporter gene in most, if not all, of the mesoderm cells starting from stage 11 (Fig. 3I,J; Brand and Perrimon 1993). Overexpression of wild-type Dracl has no effect on embryonic viability. However, expression of all three mutants with GAL424B causes embryonic lethality (Table 1). Again, the V12

Figure 6. Embryos expressing mutant Dracl proteins in mesoderm exhibit myoblast fusion defects, as revealed by anti-muscle MHC staining. $(A, B)$ In a stage-16 wild-type embryo (ventral-lateral view), multinucleated muscle fibers form highly ordered segmentally repeated arrays. $(C, D)$ In a stage-16 GAL4-24B; UAS-Drac1V12 embryo (ventral-lateral view), segmentally repeated MHC-positive cells fail to fuse with each other. $(E, F, H)$ In stage-16 GAL4-24B; UAS-Drac1L89 embryos, some ventral muscles generate excessive fusion $(F$, bracketed). Occasionally, muscles from the left and right hemisegments appear to fuse with each other ( $H$, open arrow; ventral view of an embryo with anterior up). $(G, I, I)$ In GAL4-24B;UAS-Drac1N17 embryos at stage 14, most MHC-positive cells were unfused $(G$, ventral lateral view). Fewer MHC-positive cells remain at stage $16(I, J$, lateral view). Cruciform fibers $(J$, bracketed) are observed, similar to those seen in GAL4-24B; UAS-Drac1L89 embryos (data not shown). Solid arrows in each are aligned with the ventral midline. Pictures of the right panel are $4 \times$ magnified compared with those of the left panel. 
mutation gives the most dramatic phenotype. The dying embryos not only are motionless but also exhibit several
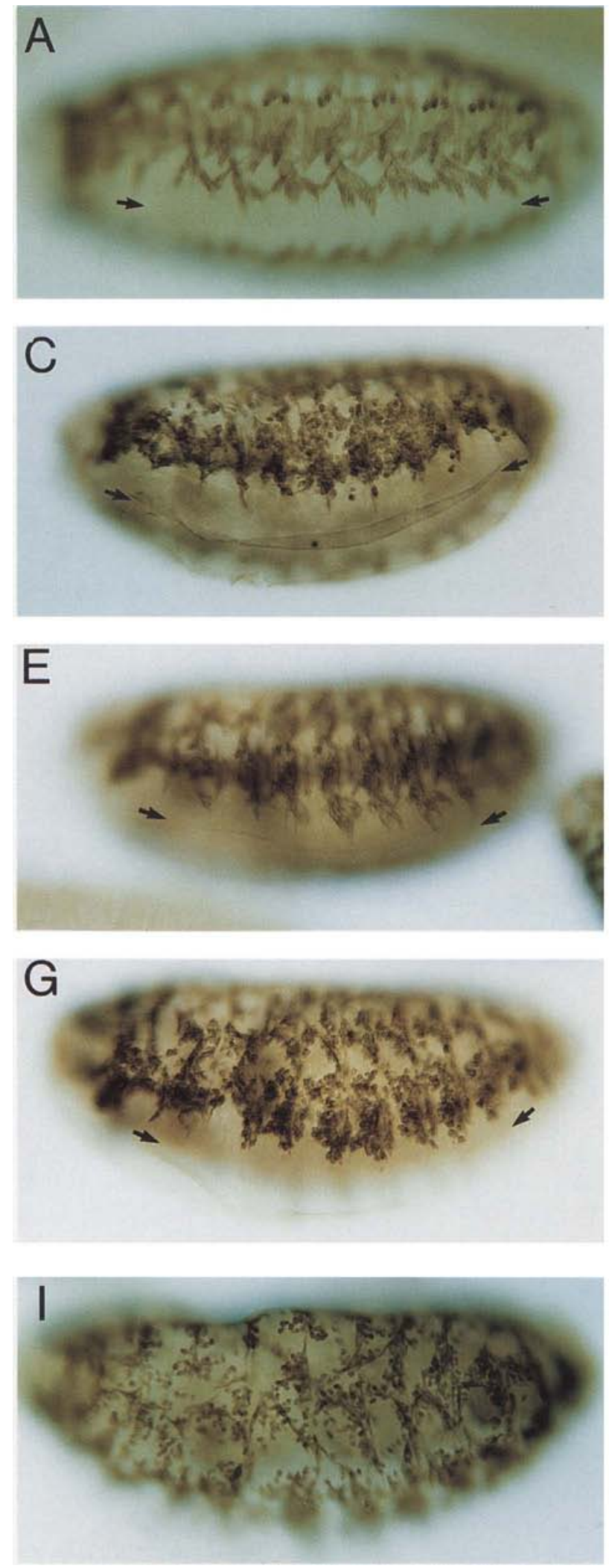

obvious defects such as tracheal and gut abnormalities (data not shown).
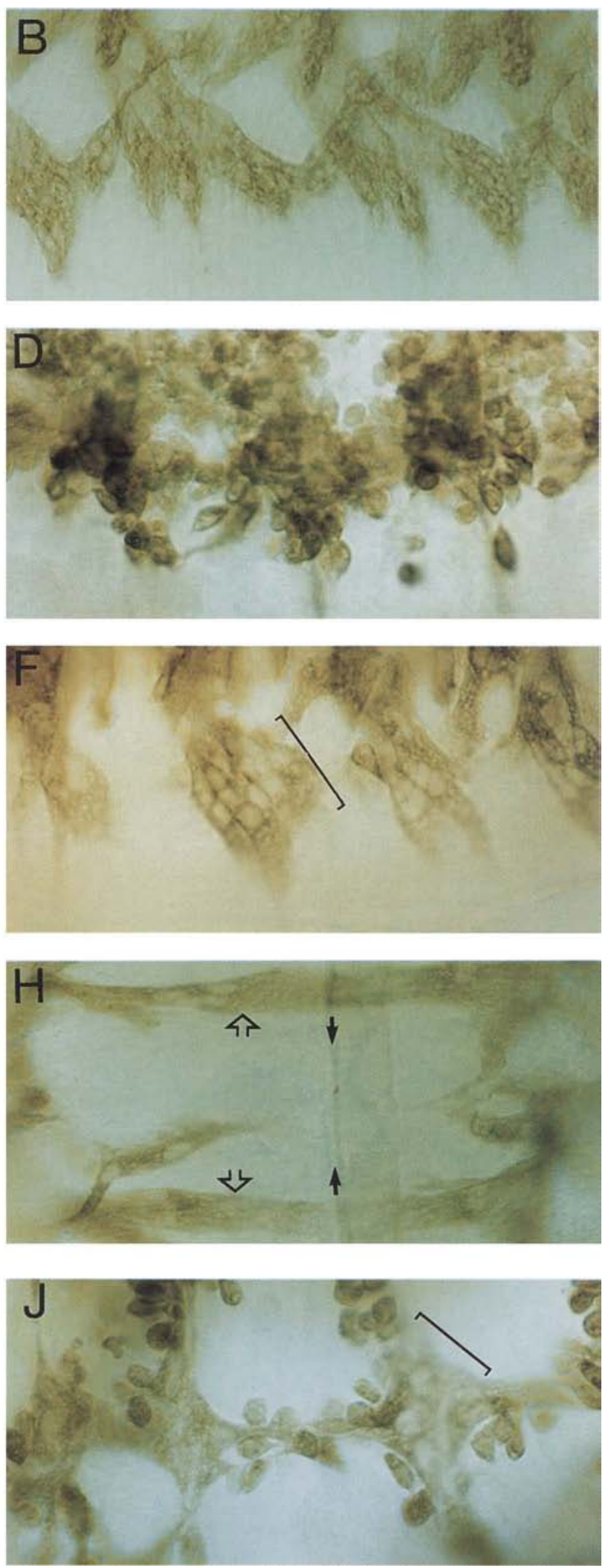

Figure 6. (See facing page for legend.) 
In wild-type embryos, after the completion of cell division and commitment to myogenic cell fate, myoblasts start to fuse at the end of stage 11 (Bate 1990). When myoblast fusion is completed at stage 14 , the multinucleated muscle cells begin to express muscle-specific markers such as muscle myosin heavy chain (MHC) (Kiehart and Feghali 1986; Fig. 6A,B). In GAL4. 24B;UAS-Drac1V12 (constitutively active) embryos, MHC-positive cells retain segmentally repeated pattern as in wild-type, but myoblast fusion is completely blocked throughout somatic mesoderm in all stages examined (Fig. 6C,D; data not shown).

Expression of the dominant-negative Drac1N17 and L89 mutants delays myoblast fusion initially and then causes excessive fusion. At stage 14 we found many MHC-positive cells with single nuclei in embryos expressing either mutant (Fig. 6G; data not shown). At later stages there are significantly fewer MHC-expressing cells in GAL4-24B;UAS-Drac1N17 embryos (Fig. 6I,J). The remaining MHC-positive cells form thin fibers that do not resemble the wild-type pattern. Novel cruciformshaped fibers, most likely resulting from the fusion of horizontal and vertical muscle fibers, are formed (Fig. 6J, bracketed). Even though most of the fibers occupy close to wild-type position (Fig. 6E,F), GAL4-24B;UASDrac1L89 embryos also exhibit cruciform-shaped fusions in the lateral clusters (data not shown), excessive fusion in the ventral-most region (Fig. 6F, bracketed), as well as abnormal fusion involving the ventral-most muscles from the left and the right hemisegments across the midline (Fig. $6 \mathrm{H}$, open arrows). These excessive fusions were never observed in wild type.

Similar to what we found in the nervous system, Dracl also appears to affect only a specific aspect of muscle differentiation. Even though fusion is completely inhibited, GAL4-24B;UAS-Drac1V12 embryos still express muscle-specific $\beta 3$-tubulin transcripts (Leiss et al. 1988) at stage 15 (Fig. 7, cf. B with A), and the cell surface adhesion protein connectin (Nose et al. 1992; Meadows et al. 1994) in similar positions as in wild-type at stage 13 (Fig. 7, cf. D with C) and at later developmental stages (Fig. 7, cf. F with E). The correct regional distribution of connectin in the mutant embryos (Fig. 7C-F) suggests that DraclV12 expression does not affect either the overall muscle pattern or muscle-specific gene expression.

\section{Dcdc42 mutants cause distinct morphological defects in neurons and muscles}

We wondered whether dominant Dracl phenotypes reflected the normal function of the wild-type Dracl protein. An alternative possibility would be that the dominant Dracl proteins are interfering with the functions of other related GTPases by competing for limiting factors such as exchange factors or effectors. To test this we took advantage of the fact that Dcdc42 has a similar expression pattern and is $70 \%$ identical to Dracl (Among all identified GTPases, the only one that is more similar to Dracl than Dedc42 is Drac2, which has a different expression pattern). We reasoned that if we were merely perturbing the function of small GTPases in general, analogous mutants V12 and N17 of Dcdc42 would have similar phenotypes as those of Dracl mutants. Conversely, if the phenotypes were distinct, then the two GTPases would be likely to play distinct roles and the dominant phenotypes generated would reflect the wildtype functions.

We found that expressing constitutively active Dcdc 42 in the nervous system (GAL4-1407;UAS-Dcdc42V12) resulted in $100 \%$ embryonic lethality (Table 1), similar to expressing the analogous mutation in Dracl. However, the PNS neuronal morphology, as revealed by $\mathrm{mAb}$ $22 \mathrm{C} 10$ staining, is qualitatively distinct (Fig. 8A,B). Unlike wild-type and Drac1 mutants which contains elongated dorsal clusters (Fig. 4), GAL4-1407;UASDcdc42V12 embryos tend to form shorter and rounder dorsal clusters (Fig. 8B). Not only are axons missing between dorsal and lateral clusters in a subset of the segments (Table 2), the dendrites (such as the dorsal external sensory dendrites; Fig. 8A, arrowheads/ also tend to be abnormal or absent (Fig. 8A, open triangles). Compared with Drac1V12 mutants, expressing Dcdc42V12 in the nervous system seems to have a more general effect, including neuronal position and dendrite as well as axon outgrowth.

Unlike GAL4-24B;UAS-Drac1V12, most of the GAL4-24B;UAS-Dcdc42V12 embryos (expressing constitutively active Dcdc42 in mesoderm) are mobile at later stages and a small percentage hatches (Table 1). The muscle fibers in these animals, as revealed by MHC antibody staining, are clearly abnormal in shape (Fig. $8 \mathrm{C}, \mathrm{D}$, arrows). They tend to form spindle, rather than the tubular, fibers in wild type (Fig. 6A,B). The muscle pattern is also not entirely normal (Fig. 8C,D, cf. with Fig. 6A,B). In sharp contrast with the analogous mutants of Dracl, which results in complete failure of myoblast fusion (Fig. 6C,D), almost all MHC-positive cells in GAL424B; UAS-Dcdc42V12 embryos are multinucleated (Fig. $8 D$ ), indicating that myoblast fusion is not affected. In GAL4-24B;UAS-Dcdc42N17 (dominant-negative) embryos the muscle fibers are mostly wild type (Fig. $8 \mathrm{E}$ ), with subtle defects in certain segments (Fig. 8F, open arrows). Again, this is in contrast with the analogous mutant in Drac1, which causes severe fusion defects (Fig. 6G,IJJ). In summary, we found that expression of constitutively active and dominant-negative Dcdc42 mutants cause phenotypes in both the nervous system and muscle that are qualitatively different from those of the corresponding Dracl mutants.

\section{Discussion}

In this paper we present evidence that expression of constitutively active or dominant-negative Dracl proteins in neurons and muscle precursors perturbs axon outgrowth and myoblast fusion, respectively. Expressing the analogous mutants of a highly related GTPase, Dcdc42, causes qualitatively different phenotypes. At this point we cannot rule out the possibility that the dominant mutants of these GTPases affect the activity of other 

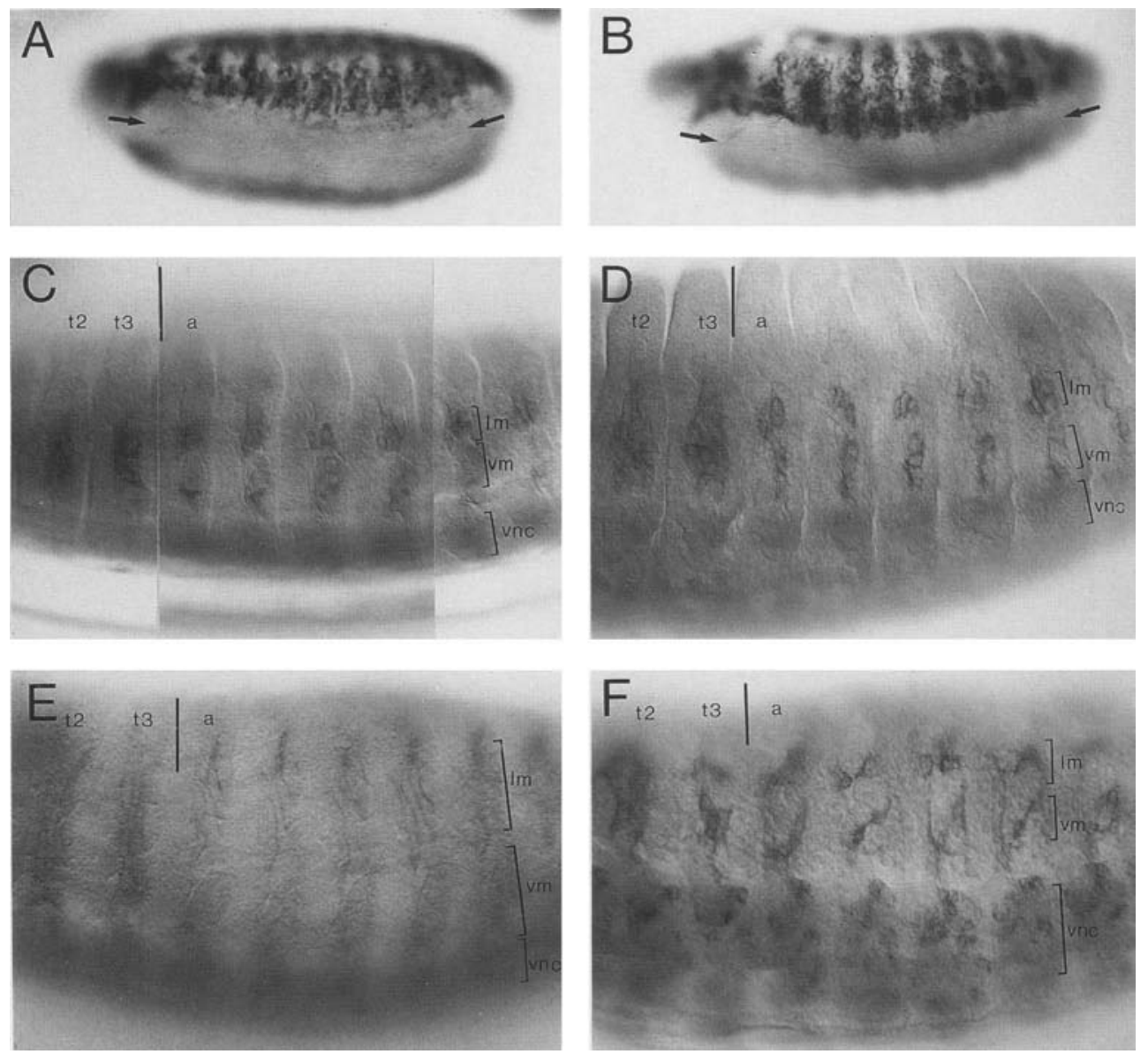

Figure 7. Normal spatial and temporal expression of muscle differentiation markers in GAL4-24B; UAS-Drac1V12 embryos. (A,B) Similar expression patterns of the $\beta 3$-tubulin transcripts (revealed by in situ hybridization with a $\beta 3$-tubulin probe) in stage-15 wild-type $(A)$ and GAL4-24B; UAS-Drac1V12 embryos $\langle B\rangle$ (both ventral-lateral views). Arrows indicate the ventral midline. $(C-F)$ Connectin is expressed on the cell surface of a subset of myoblasts that occupy the same position in wild-type $(C)$ and $G A L 4-24 B$; $U A S-D r a c 1 V 12$ embryos $(D)$ just before fusion at stage 13. At stage 15, connectin is expressed on the surface of several lateral and ventral muscle fibers in wild type $(E)$ and in corresponding positions in GAL4-24B; UAS-Drac1V12 unfused myoblasts $(F)$. C-E are lateral views, and $F$ is a ventral-lateral view. $(\mathrm{lm})$ lateral muscles; $(\mathrm{vm})$ ventral muscles; $(\mathrm{vnc})$ ventral nerve cord; $(\mathbf{t})$ thoracic segment; (a) abdominal segment.

unidentified GTPases. Nevertheless, the distinct phenotypes of Dracl and Dedc42 dominant mutations suggest that the mutant proteins do not simply perturb GTPases in general but rather affect the activity of the wild-type counterparts with some specificity and that we can infer from the mutant phenotype the wild-type function of the proteins. Accordingly, we suggest that Dracl is involved in specific aspects of neuronal and muscle morphogenesis, particularly axon but not dendrite outgrowth, and myoblast fusion. In contrast, Dcdc42 appears to be involved in more general aspects of morphogenesis and patterning in both cell types.

\section{Drac1 functions in morphogenesis}

The phenotypes generated by expressing mutant Dracl in neurons and muscles can be interpreted in two ways. First, Dracl may be involved in the signaling process leading to the differentiation of these cell types. For instance, the small GTPase Ras has been shown in both vertebrates and invertebrates to be involved in such a differentiation signaling pathway (Bar-Sagi and Feramisco 1985; Beitel et al. 1990; Simon et al. 1991). Alternatively, Dracl could participate in executing the morphogenetic process after the differentiation signal has been properly received and interpreted.

Several lines of evidence indicate that Dracl plays the latter function in both the nervous and the muscle systems. First, the number, location, and pattern of mAb 22C10- or MHC-staining cells are not changed in mutant embryos (except in the late stage of muscle development in GAL4-24B; UAS-Drac1N17 embryos). Second, molecules that are only associated with differentiated neurons or muscles, such as the mAb 22C10 antigen (Fig. 4), the HRP antigen, and synaptotagmin (data not shown) in neurons and MHC (Fig. 6), B3-tubulin (Fig. 7A,B), and 

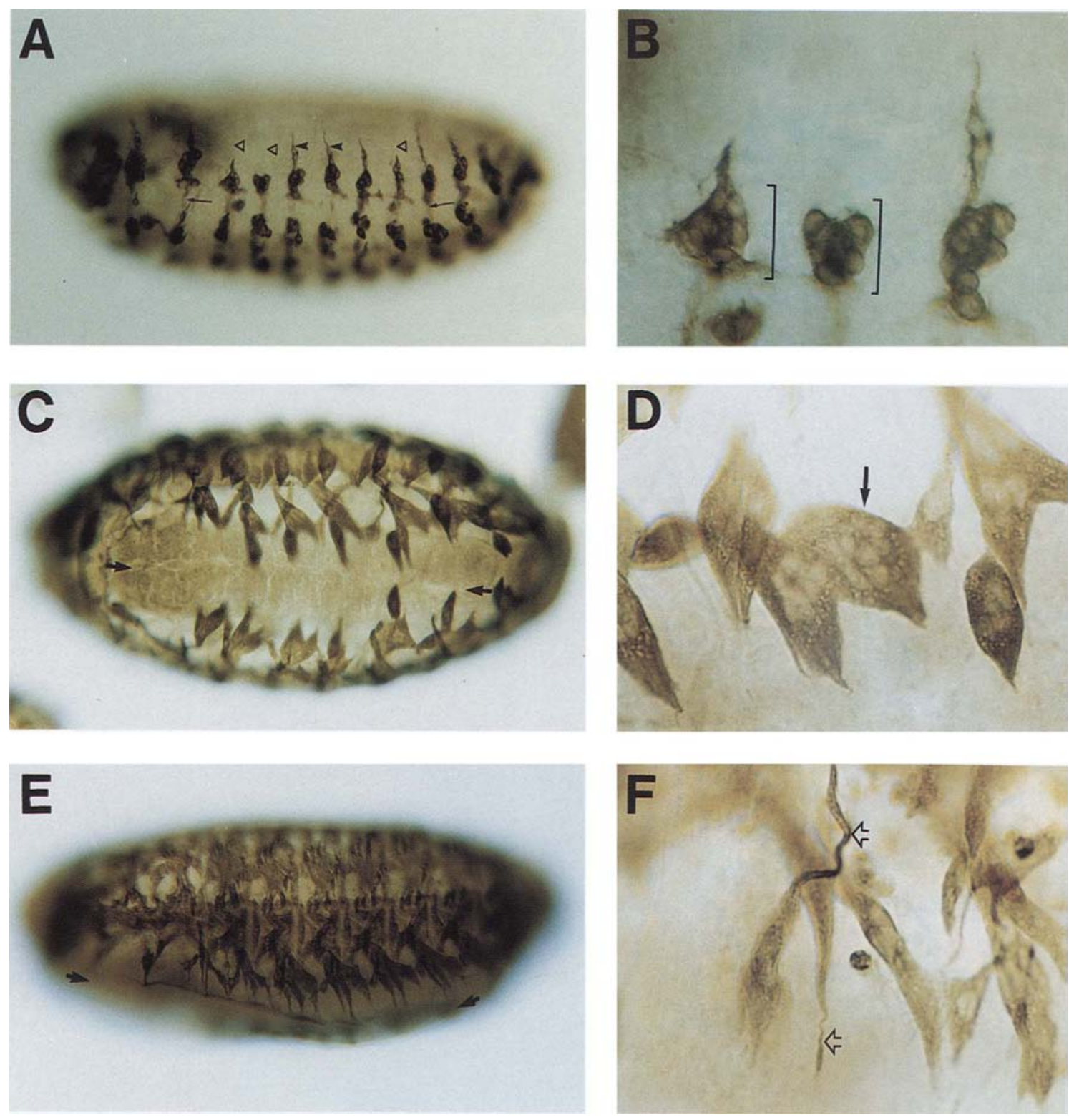

Figure 8. Distinct morphological defects in both neurons and muscles caused by expressing mutant $\mathrm{Dcdc} 42$. $(A, B) \mathrm{mAb} 22 \mathrm{C} 10$ staining of a stage-16 GAL4-1407; UAS-Dcdc42V12 embryo (dorsal-lateral view, 4× magnified in $B$ ) reveals defects in cell positions, dendrites as well as axons in the dorsal clusters of the PNS. The dorsal clusters are shorter and rounder (bracketed in $B$ ) compared with elongated dorsal clusters in wild-type and Dracl mutants (Fig. 4). Arrowheads and arrows indicate dendrites and axons that are approximately wild type, whereas triangles indicate the defective dendrites. For this particular embryo only one segment is completely missing the axons between the dorsal and lateral cluster after viewing at different focal planes (see Table 2 for the quantitation). (C,D) MHC staining of two stage-16 GAL4-24B; UAS-Dcdc42V12 embryos (ventral views, $4 \times$ magnified in $D$ ) reveals the abhormal morphology of the muscle fibers. The muscle fibers tend to be broader and shorter, and the patterns are not entirely normal compared with wild type (Fig. 6A,B). However, almost all MHC-positive cells are multinucleated (arrow in $D$ ). $(E, F)$ MHC staining pattern of two stage-16 GAL4-24B;UAS-Dcdc42N17 embryos (ventral lateral view, $4 \times$ magnified in $F$ ) is nearly normal. Occasional narrow and abnormal fibers can be observed in the ventral-most muscles (open arrows in $F$, cf. to wild type in Fig. $6 \mathrm{~B}$ ). Short arrows in $C$ and $E$ point to the ventral midline.

connectin (Fig. 7C-F) in muscles are still present in the embryos expressing mutant Dracl proteins. In contrast, expressing V12 mutant of Ras in the mammalian C2 muscle cell line completely blocks myoblast fusion as well as MHC and other muscle-specific gene expression
(Olson et al. 1987). Third, a certain degree of morphological differentiation does occur in embryos expressing mutant Dracl. In the nervous system, although the axons are missing, the dendrites are still present. Although it remains possible that the relatively late onset of the 
transgene expression prevented us from perturbing Drac1's function in the differentiation signaling process, if there is any, our results certainly indicate that Dracl plays a significant role in morphogenesis.

\section{Implication for neuronal morphogenesis}

Although neurons are highly polarized cells and dendrites are clearly different from axons in morphology, cytoskeleton components, membrane protein, and lipid distribution and functions, the mechanism that generates this polarity is not well understood/Craig and Banker 1994). This problem has been mainly studied using primary cultured neurons (Dotti et al. 1988). In the cell culture system it has been shown in antisense inhibition experiments that the microtubule-associated proteins Tau and MAP2 are essential for axons and minor processes, respectively (Caceres and Kosik 1990; Caceres et al. 1992).

Our experiments provide an in vivo demonstration that the dominant mutations in Dracl can perturb the establishment of neuronal asymmetry-the initiation and elongation of axon outgrowth. Expressing mutant Dracl seems to have a specific effect on axons but not dendrites. This indicates-in contrast to the development of axon/dendrite polarity in cultured cells (Dotti et al. 1988 - that even in the earliest stage of neuronal differentiation in the developing fly embryo, the axon/dendrite asymmetry is already established. Dracl probably participates in such a decision. The fact that mutant Dcdc42 affects both dendrites and axons also supports a specific role for Dracl in axon outgrowth.

The Rac/Rho/Cdc42 subfamily of GTPases is implicated in the actin cytoskeleton membrane interaction (Ridley et al. 1992, Ridley and Hall 1992). On the other hand, actin cytoskeleton has been shown to be important for axon initiation, filopodia formation, and axon navigation (Bentley and Toroian-Raymond 1986; Forscher and Smith 1988; Lefcort and Bentley 1989). Our results that mutant Dracl blocks axon initiation and elongation tie these previous findings together. Furthermore, expressing constitutively active DraclV12, but not dominant-negative DraclL89, mutant in neurons causes abnormal F-actin distribution (Fig. 5). This experiment suggests an explanation for the apparent paradox that expression of the constitutively active and dominant-negative Dracl mutants results in similar morphological phenotype. It argues against the possibility that abnormal F-actin accumulation in the neuronal cluster is a mere consequence of abnormal axon outgrowth, and it supports the view that regulated actin polymerization is important for axonal outgrowth. The constitutively active and dominant-negative Dracl mutants may block the regulation in different steps, resulting in similar morphological consequences.

\section{Implications for muscle morphogenesis}

Myogenesis has been used extensively as a model for studying mammalian cell differentiation largely because of the convenient and well-established cell culture system (Blau et al. 1983). Over the last several years, key myogenic genes of the basic helix-loop-helix family of transcription factors have been isolated. They are responsible for activating the myogenic program such as the expression of muscle-specific proteins and the myoblast fusion both in cell culture and in vivo (for review, see Weintraub 1993). The mechanisms to carry out the morphogenetic events leading to mature muscle formation-myoblast fusion being an essential step-are poorly understood.

In Drosophila, embryonic muscle pattern formation has been studied extensively in recent years (for review, see Bernstein et al. 1993). Genetic and anatomical analyses of muscle development (Bate 1990; Dohrmann et al. 1990; Michelson et al. 1990) have led to the hypothesis that for every muscle fiber there is a founder cell. Other fusion-competent cells will fuse with the founder cell to form patterned muscle fibers (Bate 1990). Thus, the patterning information could be encoded by the specification of founder cells. In addition, fusion-competent cells must know to which founder cell they should fuse.

When Dracl mutant proteins are expressed in the muscle precursors, myoblasts fail to fuse properly. This could be hypothesized as the result of the change of cell fate of the founder cells so that they no longer are able to fuse with the fusion-competent cells. Alternatively, Dracl may be directly involved in regulating the fusion process itself. We favor the latter possibility because (1) Drac1 is expressed ubiquitously in somatic muscle precursors (Fig. 2B), and (2) expression of dominant-negative Dracl generates excessively fused muscle fibers in later developmental stages; such excessively fused muscle fibers can be interpreted as an opposite phenotype as the lack of fusion caused by expression of constititively active Dracl.

Cell adhesion has been shown previously to be important for myoblast fusion (Knudsen et al. 1990a,b; Rosen et al. 1992). Our results implicate the involvement of an intracellular small GTPase known to affect actin cytoskeleton in the regulation of fusion, suggesting that there is potential link between the two systems.

\section{Distinct roles in morphogenesis by highly related GTPases}

The qualitatively different phenotypes generated by expressing dominant Dcdc42 mutants in neurons and muscles not only serve as controls for the specificity of Dracl's effect but also offer insight into the in vivo function of Dcdc42 itself. In neurons, Dcdc42 seems to affect a more general aspect of morphogenesis, including cell positioning, which might be a consequence of abnormal cell migration, and dendrite as well as axonal outgrowth. In muscles, Dcdc42 affects the shape and pattern of the muscle fibers, which might also be an indirect consequence of myoblast not migrating to the correct position before fusion. We suggest that in addition to affecting cell division in budding yeast, this phylogenetically highly conserved GTPase also plays a role in the mor- 
phogenesis of different cell types in multicellular organisms.

Dcdc 42 shares $70 \%$ amino acid sequence identity with Dracl. The fact that the constitutively active (V12) mutants give mostly nonoverlapping phenotypes /with the exception that both seem to affect axon outgrowth in neurons) implies that they can distinguish their distinct effectors with precision. Another interesting point is that two different putative dominant-negative mutations seem to have differential effects in different tissues. In muscle, DraclN17 mutation has a stronger phenotype than DraclL89, whereas in neurons Drac1L89 causes axon loss while no detectable morphological phenotype could be observed with Drac1N17.

Rho, Rac, and Cdc42 exhibit high sequence similarity and fall into the same subfamily of small GTPases implicated in actin cytoskeleton organization in fibroblast (Ridley and Hall 1992; Ridley et al. 1992) and bud site assembly in yeast (Drubin 1991). In this study we extend the biological function played by this class of molecules into the development of multicellular organisms and show that these similar GTPases may play distinct roles in morphogenesis in vivo. Dracl is specifically involved in axonal outgrowth in neurons and in myoblast fusion in muscle. Because neither of these processes is well understood in mechanistic terms, our findings open up a way to further dissect both of these processes using Drosophila genetics.

\section{Materials and methods}

\section{Cloning of Dracl and Dcdc42}

Two primer pairs were used for reverse transcription-PCR amplification. The first pair [forward: $5^{\prime}-\mathrm{GA}(\mathrm{C} / \mathrm{T}) \mathrm{ACIGCIGGI-}$ CA(A/G)GA(A/G)GAITA-3' ; reverse: 5'-ATIGC(T/C)TC(A/ G)TC(A/G)AAIACI/G/T)T-3'] corresponds to a region common to human and yeast $\mathrm{Cdc} 42$ as well as their closest relatives (Shinjo et al. 1990), human Racl and Rac2 (amino acids 57-64 and $168-173$ of $\mathrm{Cdc} 42 / \mathrm{Rac})$. The second pair [forward: $5^{\prime}-\mathrm{AA} / \mathrm{C} /$ T)TA/C/T)GCIGTIACIGTIATGAT(A/C/T)GG-3'; reverse: $5^{\prime}$ ATIGC(T/C)TC(A/G)TC(A/G)AAIACI/G/T)T-3'] is specific for yeast and human Cdc42 (amino acids $39-47$ and 150-157) (Shinjo et al. 1990). Total RNA was prepared from 4- to $12-\mathrm{hr}$ Drosophila embryos (Jowett 1986) and used as template for RTPCR using Invitrogen's cDNA Cycle Kit. PCR conditions were $94^{\circ} \mathrm{C} 3^{\prime}$ for denaturation, followed by 40 cycles of $94^{\circ} \mathrm{C}$ for 1 $\min , 45^{\circ} \mathrm{C}$ for $1 \mathrm{~min}$, and $72^{\circ} \mathrm{C}$ for $3 \mathrm{~min}$, and ended by $72^{\circ} \mathrm{C}$ for $7 \mathrm{~min}$. PCR products were subcloned by blunt-end ligation into Bluescript plasmid (Stratagene), digested with EcoRV and subjected to double-stranded DNA sequencing according to standard protocol (Sequenase kit, U.S. Biochemical).

Two very similar genes, Drac1 and Drac2, were identified by PCR with the first pair of oligonucleotides. The PCR fragments encode two polypeptides that share $92 \%$ amino acid sequence identity. We focused on Drac1 for further studies because it is expressed in muscle precursors during muscle differentiation and in the nervous system during axonogenesis. In contrast, Drac2 is highly enriched in the visceral mesoderm. A single gene, $D c d c 42$, was identified with the second pair of the primers.

The PCR products of Drac1 and Dcdc42 were digoxigeninlabeled (Boehringer Mannheim) and used as probes to screen the
Kauvar cDNA library made from 0- to 12-hr Drosophila embryos. For Drac1, a 1.7-kb cDNA containing the entire ORF was isolated and cloned into Bluescript as an EcoRI fragment. It has about a 300-bp 5'-untranslated region (5' UTR) and an 800-bp $3^{\prime}$-untranslated region (3' UTR). For $D c d c 42$, a $1.65-\mathrm{kb}$ cDNA was identified that contains the entire ORF, a 180-bp 5' UTR, and $\sim 850$-bp 3' UTR. The nucleotide sequences encompassing the ORF of both genes were determined by sequencing the cDNAs from both directions using oligonucleotides as primers.

\section{Site-directed mutagenesis and DNA constructs}

Drac1 and Dcdc42 cDNAs in Bluescript were used as templates for site-directed mutagenesis with Amersham's in vitro mutagenesis system (Nakamaye and Eckstein 1986). Mutations were confirmed by DNA sequencing. Wild-type and mutant Drac1 and Dcdc42 cDNAs were then digested with EcoRI and inserted into the polylinker of the transformation vector pUAST (Brand and Perrimon 1993).

For the generation of the elav-GAL4 construct, first the SV40 poly(A) trailer from pUAST was cloned into Bluescript (SK -) NotI and BamHI sites. The above construct was cut with SacII, blunt-ended with T4 DNA polymerase, cut with NotI, and ligated to a 3.5-kb EcoRV-NotI-digested fragment that contains the promoter region of the Drosophila gene elav. The construct generated above was digested at the NotI site between the elav promoter and the SV40 poly(A) and ligated to a NotI fragment containing the GAL4-coding region derived from the HindIII fragment of the vector pGATN (Brand and Perrimon 1993). The construct then was digested with EcoRI and inserted into the transformation vector CaSpeR (Pirrotta 1988).

\section{Germ-line transformation and genetics}

Germ-line transformation was performed according to standard procedure (Spradling and Rubin 1982). Transformants with $w^{+}$ eye color were mapped and homozygosed with the help of a double balancer stock $w ; T(2 ; 3) A t a / C y O ; T m 3 S b$. To look for phenotypes generated by expressing mutant Dracl and Dcdc42 in different tissues, we crossed homozygous GAL4 lines (1407, 60, elav-GAL4, and 24B) to homozygous UAS-Drac1 and UAS$D c d c 42$, respectively, so that $100 \%$ embryos are of the same genotype.

\section{In situ hybridization and immunocytochemistry}

Digoxigenin-labeled RNA probes were used for embryo in situ hybridization according to methods described previously (Tautz and Pfeifle 1989|. For HRP-immunocytochemistry, embryo fixation was done according to methods previously described (Bodmer and Jan 1987). After devitellinization, embryos were rehydrated in $0.1 \mathrm{M}$ phosphate buffer $(\mathrm{pH} 7.2)$ with $0.1 \%$ Triton $\mathrm{X}-100$ (PBT) and blocked with $5 \%$ normal goat serum for onehalf hour at room temperature. All primary antibody incubations were done at $4^{\circ} \mathrm{C}$ overnight with the specific conditions listed below. Rabbit anti- $\beta$-galactosidase (Cappel), preabsorbed against 0 - to 17-hr embryos, (1:5000); goat anti-HRP (Cappel) (1:1000); mAb 22C10 (Fujita et al. 1982; gift from S. Benzer) (1:150); rabbit anti-synaptotagmin (Littleton et al. 1993, gift from J.T. Littleton and H. Bellen), preabsorbed against $0-$ to $9-\mathrm{hr}$ embryos (1:500); rabbit anti-MHC (Kiehart and Feghali 1986, gift from D. Kiehart) (1:500); mouse anti-connectin monoclonal (Meadows et al. 1994, gift from R. White), preabsorbed against 0to 9-hr embryos $(1: 10)$. Anti- $\beta$-galactosidase and anti-MHC antibody stainings were amplified with Vectastain $\mathrm{ABC}$ kit according to manufacturer's specifications. The rest were recog- 
nized by secondary antibody conjugated with HRP (Bio-Rad). The stainings were developed in $100 \mathrm{~mm}$ Tris $(\mathrm{pH} 7.5)$ with 0.2 $\mathrm{mg} / \mathrm{ml}$ of diaminobenzidine and $0.06 \% \mathrm{H}_{2} \mathrm{O}_{2}$.

\section{Phalloidin staining and confocal microscopy}

For double labeling with mAb $22 \mathrm{C} 10$ and phalloidin, dechorionated embryos were fixed in $5 \%$ formaldehyde/heptane for 1 hr. The embryos were transferred to double-stick tape and devitellinized manually with a 25 -gauge needle in a dish containing PBT. They were then processed for antibody staining as usual. During secondary antibody incubation (1:200 DTAF conjugated donkey-anti-mouse; Jackson Laboratory), $1 \mu \mathrm{g} / \mathrm{ml}$ of phalloidin-Texas red (Sigma) was added. The samples were mounted in $80 \%$ glycerol with $2 \%$ propyl gallate and viewed with an MRC-600 confocal microscopy. Images were processed with Altimira Composer and Photoshop programs.

\section{Acknowledgments}

We are grateful to Ira Herskowitz for discussions in the initiation of the project. We thank the following colleagues for sending us fly strains, antibodies and plasmids: G. Technau for the GAL4 enhancer trap lines 1407 and 60, B. Noll and N. Perrimon for the GAL4 line 24B, S. Benzer for mAb 22C10, J.T. Littleton and $\mathrm{H}$. Bellen for anti-synaptotagmin antibody and cDNA probe, D. Kiehart for antimuscle myosin heavy-chain antibody, K.-M. Yao and K. White for the plasmid containing elav neuronal-specific promoter, $\mathrm{R}$. White for anti-connectin antibody, and $\mathrm{T}$. Jongens for poly $(\mathrm{A})^{+}$mRNAs. We also thank E. Giniger for the initial characterization of the GAL4 lines 1407 and 60, S. Barbel for performing in situ hybridization, and L. Ackerman and W. Walantus for photography. We appreciate discussions and critical comments on the manuscript from $\mathrm{H}$. Bourne, $\mathrm{Z}$. Hall, F. Lefcort, X.C. Liao, M. Sheng, V. Siegel, and especially G. Feger and P. Kolodziej. L.L. is a Jane Coffin Childs postdoctoral fellow and L.Y.J. and Y.N.J. are investigators of the Howard Hughes Medical Institute.

The publication costs of this article were defrayed in part by payment of page charges. This article must therefore be hereby marked "advertisement" in accordance with 18 USC section 1734 solely to indicate this fact.

\section{Note added in proof}

The nucleotide sequence data for Drac1 and $D c d c 42$ have been deposited in the GenBank data library under accession numbers U11823 and U11824, respectively.

\section{References}

Bar-Sagi, D. and J.R. Feramisco. 1985. Microinjection of the ras oncogene protein into $\mathrm{PCl} 2$ cells induces morphological differentiation. Cell 42: 841-848.

Barbacid, M. 1987. ras genes. Annu. Rev. Biochem. 56: 779-827.

Bate, M. 1990. The embryonic development of larval muscles in Drosophila. Development 110: 791-804.

Beitel, G.J., S.G. Clark, and H.R. Horvitz. 1990. Caenorhabditis elegans ras gene let-60 acts as a switch in the pathway of vulval induction. Nature 348: 503-509.

Bender, A. and J.R. Pringle. 1989. Multicopy suppression of the cdc24 budding defect in yeast by CDC42 and three newly identified genes including the ras-related gene RSR1. Proc. Natl. Acad. Sci. 86: 9976-9980.

Bentley, D. and A. Toroian-Raymond. 1986. Disoriented path- finding by pioneer neurone growth cones deprived of filopodia by cytochalasin treatment. Nature 323: 712-715.

Bernstein, S.I., P.T. O’Donnell, and R.M. Cripps. 1993. Molecular genetic analysis of muscle development, structure, and function in Drosophila. Int. Rev. Cytol. 143: 63-152.

Blau, H.M., C.P. Chiu, and C. Webster. 1983. Cytoplasmic activation of human nuclear genes in stable heterokaryons. Cell 32: 1171-1180.

Bodmer, R. and Y.N. Jan. 1987. Morphological differentiation of the embryonic peripheral neurons in Drosophila. Wilhelm Roux's Arch. Dev. Biol. 196: 69-77.

Bourne, H.R., D.A. Sanders, and F. McCormick. 1991. The GTPase superfamily: Conserved structure and molecular mechanism. Nature 349: 117-127.

Brand, A.H. and N. Perrimon. 1993. Targeted gene expression as a means of altering cell fates and generating dominant phenotypes. Development 118: 401-415.

Caceres, A. and K.S. Kosik. 1990. Inhibition of neurite polarity by tau antisense oligonucleotides in primary cerebellar neurons. Nature 343: 461-463.

Caceres, A., J. Mautino, and K.S. Kosik. 1992. Suppression of MAP2 in cultured cerebellar macroneurons inhibits minor neurite formation. Neuron 9: 607-618.

Campos-Ortega, J. A. and V. Hartenstein. 1985. The embryonic development of Drosophila melanogaster. Springer-Verlag, New York.

Chant, J. and I. Herskowitz. 1991. Genetic control of bud site selection in yeast by a set of gene products that constitute a morphogenetic pathway. Cell 65: 1203-1212.

Chant, J., K. Corrado, J.R. Pringle, and I. Herskowitz. 1991. Yeast $B U D 5$, encoding a putative GDP-GTP exchange factor, is necessary for bud site selection and inteRacts with bud formation gene BEM1. Cell 65: 1213-1224.

Craig, A.M. and G. Banker 1994. Neuronal polarity. Annu. Rev. Neurosci. 17: 267-310.

Didsbury, J., R.F. Weber, G.M. Bokoch, T. Evans, and R. Snyderman. 1989. Rac, a novel ras-related family of proteins that are botulinum toxin substrates. I. Biol. Chem. 264: 1637816382.

Dohrmann, C., N. Azpiazu, and M. Frasch. 1990. A new Drosophila homeo box gene is expressed in mesodermal precursor cells of distinct muscles during embryogenesis. Genes \& Dev. 4: 2098-2111.

Dotti, C.G., C.A. Sullivan, and G.A. Banker. 1988. The establishment of polarity by hippocampal neurons in culture. $J$. Neurosci. 8: 1454-1468.

Drubin, D.G. 1991. Development of cell polarity in budding yeast. Cell 65: 1093-1096.

Feig, L.A. and G.M. Cooper. 1988. Inhibition of NIH3T3 cell proliferation by a mutant ras protein with preferential affinity for GDP. Mol. Cell. Biol. 8: 3235-3243.

Forscher, P. and S.J. Smith. 1988. Actions of cytochalasins on the organization of actin filaments and microtubules in a neuronal growth cone. J. Cell Biol. 107: 1505-1516.

Fujita, S.C., S.L. Zipursky, S. Benzer, A. Ferrusa, and S.L. Shotwell. 1982. Monoclonal antibodies against the Drosophila nervous system. Proc. Nat1. Acad. Sci. 79: 7929-7933.

Ghysen, A., C. Dambly-Chaudiere, L.Y. Jan, and Y.N. Jan. 1993. Cell interactions and gene interactions in peripheral neurogenesis. Genes \& Dev. 7: 723-733.

Han, M. and P.W. Sternberg. 1991. Analysis of dominant-negative mutations of the Caenorhabditis elegans let-60 ras gene. Genes \& Dev. 5: 2188-2198.

Hart, M.J., A. Eva, T. Evans, S.A. Aaronson, and R.A. Cerione. 1991. Catalysis of guanine nucleotide exchange on the $\mathrm{CDC} 42 \mathrm{Hs}$ protein by the $d b l$ oncogene product. Nature 
354: 311-314.

Hartenstein, V. 1988. Development of Drosophila larval sensory organs: Spatialtemporal pattern of sensory neurones, peripheral axonal pathways and sensilla differentiation. Development 102: 869-886.

Jan, L.Y. and Y.N. Jan. 1982. Antibodies to horseradish peroxidase as specific neuronal markers in Drosophila and in grasshopper embryos. Proc. Natl. Acad. Sci. 79: 2700-2704.

Johnson, D.I. and J.R. Pringle. 1990. Molecular characterization of $C D C 42$, a Saccaromyces cerevisiae gene involved in the development of cell polarity. J. Cell Biol. 111: 143-152.

Jowett, T. 1986. Hot phenol method for total RNA. In Drosophila: A practical approach (ed. D.B. Roberts), p. 279. IRL Press, Oxford, UK.

Kiehart, D.P. and R. Feghali. 1986. Cytoplasmic myosin from Drosophila melanogaster. I. Cell Biol. 103: 1517-1525.

Knudsen, K.A., S.A. McElwee, and L. Myers. 1990a. A role for the neural cell adhesion molecule, NCAM, in myoblast inteRaction during myogenesis. Dev. Biol. 138: 159-168.

Knudsen, K.A., L. Myers, and S.A. McElwee. 1990b. A role for the $\mathrm{Ca} 2|+|$-dependent adhesion molecule, $\mathrm{N}$-cadherin, in myoblast interaction during myogenesis. Exp. Cell Res. 188: 175-184.

Lefcort, F. and D. Bentley 1989. Organization of cytoskeletal elements and organelles preceding growth cone emergence from an identified neuron in-situ. $J$. Cell Biol. 108: 17371749.

Leiss, D., U. Hinz, A. Gasch, R. Mertz, and R. Renkawitz-Pohl. 1988. $\beta 3$ tubulin expression characterizes the differentiating mesodermal germ layer during Drosophila embryogenesis. Development 104: 525-531.

Littleton, J.T., H.J. Bellen, and M.S. Perin. 1993. Expression of synaptotagmin in Drosophila reveals transport and localization of synaptic vesicles to the synapse. Development 118: $1077-1088$.

Meadows, L.A., D. Gell, K. Broadie, A.P. Gould, and R.A.H. White. 1994. The cell adhesion molecule, connectin, and the development of the Drosophila neuromuscular system. $I$. Cell Sci. 107: 321-328.

Michelson, A.M., S.M. Abmayr, M. Bate, A.M. Arias, and T. Maniatis. 1990. Expression of a MyoD family member prefigure muscle pattern in Drosophila embryos. Genes \& Dev. 4: 2086-2097.

Nakamaye, K.L. and F. Eckstein. 1986. Inhibition of restriction endonuclease Nci I cleavage by phosphorothioate groups and its application to oligonucleotide-directed mutagenesis. $\mathrm{Nu}$ cleic Acids Res. 14: 9679-9698.

Nose, A., V.B. Mahajan, and C.S. Goodman. 1992. Connectin: A homophilic cell adhesion molecule expressed on a subset of muscles and the motoneurons. Cell 70: 553-567.

Nüsslein-Volhard, C. and E. Wieschaus. 1980. Mutations affecting segment number and polarity in Drosophila. Nature 287: 795-801.

O'Connor, T.P. and D. Bentley. 1993. Accumulation of actin in subsets of pioneer growth cone filopodia in response to neural and epithelial guidance cues in situ. I. Cell Biol. 123: 935-948.

Olson, E.N., G. Spizz and M.A. Tainsky. 1987. The oncogenic forms of $\mathrm{N}$-ras or H-ras prevent skeletal myoblast differentiation. Mol. Cell. Biol. 7: 2104-2111.

Park, H.-O., J. Chant, and I. Herskowitz. 1993. BUD2 encodes a GTPase-activating protein for Budl/Rsrl necessary for proper bud-site selection in yeast. Nature 365: 269-274.

Pirrotta, V. 1988. Vectors for P-element transformations in Drosophila. In Vectors: A survey of molecular cloning vectors and their uses (ed. R.H. Rodriguez and D.T. Reinhardt), pp. 437-456. Butterworth, Boston, MA.

Powers, S., E. Gonzales, T. Christensen, J. Cubert, and D. Broek. 1991. Functional cloning of BUD5, a CDC25-related gene from $S$. cerevisiae that can suppress a dominant-negative RAS2 mutant. Cell 65: 1225-1231.

Ridley, A.J. and A. Hall. 1992. The small GTP-binding protein Rho regulates the assembly of focal adhesions and actin stress fibers in response to growth factors. Cell 70: 389-399.

Ridley, A.J., H.F. Paterson, C.L. Johnston, D. Diekmann, and A. Hall. 1992. The small GTP-binding protein rac regulates growth factor-induced membrane ruffling. Cell 70: 401-410.

Robinow, S. and K. White. 1988. The locus elav of Drosophila melanogaster is expressed in neurons at all developmental stages. Dev. Biol. 126: 294-303.

Ron, D., M. Zannini, M. Lewis, R.B. Wickner, L.T. Hunt, G. Graziani, S.R. Tronick, S.A. Aaronson, and A. Eva. 1991. A region of proto- $d b l$ essential for its transforming activity shows sequence similarity to a yeast cell cycle gene, $C D C 24$, and the human breakpoint cluster gene, bcr. New Biologist 3: 372-379.

Rosen, G.D., J.R. Sanes, R. LaChance, J.M. Cunningham, J. Roman, and D.C. Dean. 1992. Roles for the integrin VLA-4 and its counter receptor VCAM-1 in myogenesis. Cell 69: 11071119.

Rubin, G.M. 1991. Signal transduction and the fate of the R7 photoreceptor in Drosophila. Trends Genet. 7: 327-372.

Schweighoffer, F., H. Cai, M.C. Chevallier-Multon, I. Fath, G. Cooper, and B. Tocque. 1993. The Saccharomyces cerevisiae SDC25 C-domain gene product overcomes the dominant inhibitory activity of Ha-Ras asn-17. Mol. Cell. Biol. 13: 3943.

Seeger, M., G. Tear, D. Ferres-Marco, and C.S. Goodman. 1993. Mutations affecting growth cone guidance in Drosophila: Genes necessary for guidance toward or away from the midline. Neuron 10: 409-426.

Shinjo, K., J.G. Koland, M.J. Hart, V. Narasimhan, D.I. Johnson, T. Evans, and R.A. Cerione. 1990. Molecular cloning of the gene for the human placental GTP-binding protein Gp (G25K): Identification of this GTP-binding protein as the human homolog of the yeast cell-division-cycle protein CDC42. Proc. Nat1. Acad. Sci. 87: 9853-9857.

Simon, M.A., D.D. Bowtell, G.S. Dodson, T.R. Laverty, and G.M. Rubin. 1991. Rasl and a putative guanine nucleotide exchange factor perform crucial steps in signaling by the sevenless protein tyrosine kinase. Cell 67: 701-716.

Spradling, A.C. and G.M. Rubin. 1982. Transposition of cloned $\mathrm{P}$ elements into Drosophila germ line chromosomes. Science 218: 341-347.

Tautz, D. and C. Pfeifle. 1989. A non-radioactive in situ hybridization method for the localization of specific RNAs in Drosophila embryos reveals translational control of the segmentation gene hunchback. Chromosoma 98: 81-85.

Van Vactor, D., H. Sink, D. Fambrough, R. Tsoo, and C.S. Goodman. 1993. Genes that control neuromuscular specificity in Drosophila. Cell 73: 1137-1153.

Weintraub, H. 1993. The MyoD family and myogenesis: Redundancy, networks, and thresholds. Cell 75: 1241-1244.

Yao, K.-M. and K. White. 1994. Neural specificity of elav expression: Defining a Drosophila promoter that directs neural-specific expression. $J$. Neurochem. 63: 41-51. 


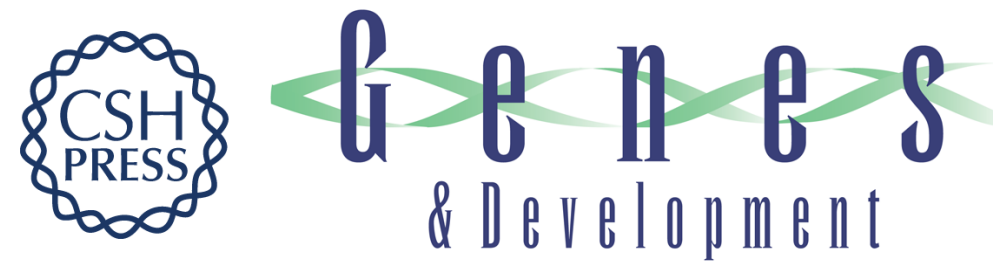

\section{Distinct morphogenetic functions of similar small GTPases: Drosophila Drac1 is involved in axonal outgrowth and myoblast fusion.}

L Luo, Y J Liao, L Y Jan, et al.

Genes Dev. 1994, 8:

Access the most recent version at doi:10.1101/gad.8.15.1787

References This article cites 59 articles, 25 of which can be accessed free at: http://genesdev.cshlp.org/content/8/15/1787.full.html\#ref-list-1

License

Email Alerting Service

Receive free email alerts when new articles cite this article - sign up in the box at the top right corner of the article or click here.

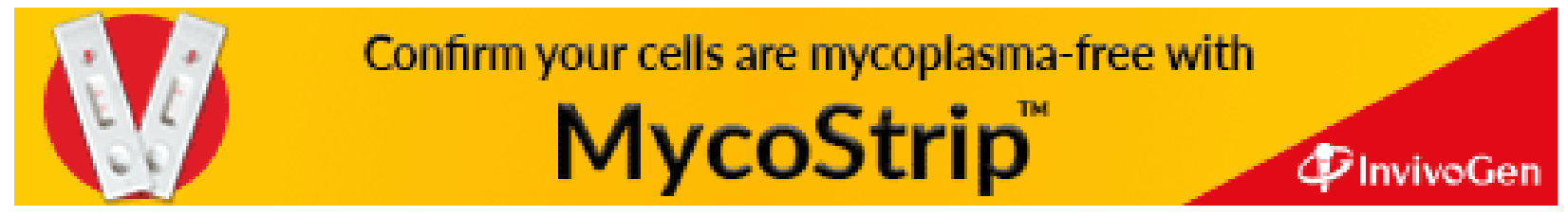

